\title{
IMPACT OF SIMULATED CLIMATE CHANGE ON SLUG GRAZING IN DESIGNED PLANT COMMUNITIES
}

\author{
AlizADEH, B. ${ }^{*}$ - HitchMOUGH, J. D. \\ Department of Landscape Architecture, The University of Sheffield, Sheffield S10 2TN, UK \\ *Corresponding author \\ e-mail:behdadalizade@gmail.com
}

(Received $8^{\text {th }}$ Sep 2019; accepted $12^{\text {th }}$ Feb 2020)

\begin{abstract}
Climate change is currently altering ecosystem services which are a supply of benefits that support human life and well-being provided by ecosystems to our society. Although recently, many studies have investigated effects of biodiversity on ecosystem functions, there is a considerable lack of studies on the responses of invertebrates to climate change. The grazing behavior of slugs is of critical importance in the sparse herbaceous vegetation of cool-temperate zones and also in the temperate regions with seasonally moist climates. They significantly influence the, development, composition and biomass of both semi-natural and designed herbaceous vegetation. This experiment aimed to investigate how the selectivity of grazing by herbivores affected relationships between plant species in designed plant communities under 2050 UK climate change scenarios. Thirty-six species from three different ecological regions were chosen to represent a gradient from well fitted to poorly fitted to the current British climate and from palatable to unpalatable to slugs. They also were selected to share the similar morphological characteristics, regarding canopy size and flower attractiveness for urban green space users. The molluscs showed different behaviours in dry, wet, warm and ambient temperature, and this led to significant differences in the biomass and structure of the plant communities.
\end{abstract}

Keywords: mollusc grazing, herbivory, meadow-like community, plant species fittness, urban landscape

\section{Introduction}

Today, much attention is paid to biodiversity and the potential impact of climate change on biodiversity. Nowadays, the "quality of life", "human well-being" and "biodiversity are three critical factors for all the landscape planner. Greenspaces are one of the most important wildlife habitats in the urban area. Urban landscape not only provide physical habitat for native and non-native fauna but also provide pollen and nectar for wild life through the plant spices and vegetation (Dunnett and Hitchmough, 2004). These habitats also support large populations of slugs and snails, and these herbivores have a reciprocal impact on the vegetation itself (Hitchmough and Wagner, 2011).

Greenhouse gases, moisture availability and temperature, are three critical factors that should be considered in climate change research. Researchers in different aspects investigated impacts of water stress on plant growth in the urban landscape. In moist temperate climates slugs and snails significantly affect the "development and composition" of herbaceous vegetation (Bruelheide and Scheidel, 1999; Wilby and Brown, 2001; Holland et al., 2007; Hitchmough and Wagner, 2011; Hitchmough et al., 2017). Mollusc herbivory is an essential element for limiting plant species distribution as it has been shown, for instance, with Arnica montana. Herbivory is vital because when combined with competition between plant species it acts to exaggerate competition, slow growing, shade-intolerant species that are palatable are likely to be eliminated much more quickly from the vegetation than unpalatable species of similar competitiveness. Food selection by snail and slug in plant communities has been 
investigated by Grime et al. (1973, 1977, 1998, 2006), Pallant (1972), Dirzo (1980), Wardle et al. (1998), Lawrey (1983), Rathke (1985), Briner and Frank (1998), Speiser and Rowell-Rahier (1993), Jennings and Barkham (1975), Hoyle et al. (2017) and Alizadeh and Hitchmough (2019a).

In most parts of the world, plant distribution will be affected by climate change. According to the IPCC (2014), climate change is estimated to exacerbate the loss of species most, where those species have restricted climate and habitat requirements, and limited migration capabilities. Thomas et al. (2004) have estimated that climate change may lead to the extinction of 3-21\% of all endemic plant species in Europe by 2050. Species composition will change in every part of Europe differently. Bakkenes et al. (2006) suggests that "The most dramatic changes will occur in Northern Europe, where more than $35 \%$ of the species composition in 2100 will be invasive, and in Southern Europe, where up to $25 \%$ of the species now present will have disappeared under the climatic circumstances forecasted for 2100" (Bakkenes et al., 2006).

On the European and other continental land masses climate change will lead to movement of species, as some existing species become less fit and current unfit species become more fitted. In the designed, culturally founded landscapes of cities reducing the climate change will need to involve parallel, but actively human-mediated processes. New plant species, from other parts of the world, which are more similar to future climate change scenarios and hence more tolerant, will become essential in designed sustainable urban landscapes (Alizadeh and Hitchmough, 2019b). Although currently in most parts of the world, alien plant species are considered as unsustainable design elements in urban landscapes (Hitchmough, 2011), in the future, these attitudes will have to change.

These incoming or alien plant species have ecological functions in the urban landscape, as do current native species. They support native invertebrates and also are attractive for people, and facilitate a range of ecosystem service functions, which are generic and not based on plant origin.

The effects of different climate change scenarios on the designed plant community in the urban area were investigated before by Alizadeh (2016). In this article, the effect of simulated climate change on slug grazing effects on three communities of varying palatability is studied. The present research appears to be the first study on food selection by slug and snail under different climate change scenarios.

\section{Materials and methods}

Planting mixes were designed as described by Ahmad and Hitchmough (2007), Sayuti and Hitchmough (2013), Alizadeh and Hitchmough (2019) to create meadowlike plant communities to test the research questions.

The undertaken criteria for plants selection in the study are as follows:

- Seed availability

- Typical fitness to UK conditions

- Canopy size, and form, morphological similarity

- Flowering period, plant height and aesthetic function of the species

- Diverse yet complementary ecological strategies

- Slug palatability

- UK 2050-2080 climate change scenarios 
The sowing mix was composed of 36 grassland forbs from the three different climatic types (Western Europe with Maritime climate (well fitted to the current UK climate), Southern Europe (intermediate in fitness to the current UK climate) and Rocky Mountain/Eurasian Steppe Region (Temperate Continental climate, poorly fitted to the current UK climate). Twelve species from each climatic type were present in the seed mix to produce a gradient of species from well fitted to poorly fitted to the current British climate. The characteristics of these species are shown in Tables 1, 2 and 3. Selection was based on many years of prior experience working with these species both in experiments and in practice, backed up by ecological strategy models developed by Grime (1977, 1979). The communities of these 36 species were then managed and manipulated to create a biological assay to investigate climate change in the form of a multi-layer (low, medium, and tall) designed meadow community and slug grazing on designed meadow community under different climate change scenarios (Tables 1, 2 and 3). These layers were important in the meadow community both in aesthetic and ecological terms, with short species (unless shade tolerant), being most likely to be eliminated due to light competition where unfit, and hence species were selected and characterised as four groupings on the basis of the predominant height of their typical mature canopy: 1: < $20 \mathrm{~cm}, 2: 20-40 \mathrm{~cm}, 3: 40-80 \mathrm{~cm}, 4:>80 \mathrm{~cm}$.

The plant species were categorized based on slug or snail palatability under current UK climate scenarios as well.

Research started in spring 2012 with site and soil preparation and the construction of 48 external growth cabins at the Sheffield Botanical Garden.

During the five years of the research, the mean annual rainfall in Sheffield was $877 \mathrm{~mm}$ and the mean annual temperature was $10^{\circ} \mathrm{C}$. The $2050-2080$ UK climate change scenarios (Theccc.org.uk, 2018) were used as the base for decisions on manipulating precipitation and temperature within the growth cabins.

\section{Climate scenarios}

The climate in the UK is maritime. The Sheffield's weather conditions of the study years (2010 to 2016) are presented in Tables 4 and 5.

Table 1. Temperate maritime climate (mostly western Europe) plant species

\begin{tabular}{c|c|c|c}
\hline Species & Habit & $\begin{array}{c}\text { Typical fitness in } \\
\text { current UK climate }\end{array}$ & Slug palatability \\
\hline Arnica montana & Rosette with ascending stem & Well fitted & Palatable \\
Bupthalmum salicifolium & Hummock & Well & Palatable \\
Centaurea montana & Hummock & Well & Palatable \\
Galium verum & Mat with ascending stem & Well & Unpalatable \\
Geranium sylvaticum & Hummock & Well & Unpalatable \\
Knautia arvensis & Hummock with ascending stem & Well & Unpalatable \\
Origanum vulgare & Hummock & Well & Unpalatable \\
Phyteuma spicatum var. coeruleum & Hummock with ascending stem & Well & Palatable \\
Primula veris & Mat with ascending stem & Well & Unpalatable \\
Prunella vulgaris & Mat with ascending stem & Well & Unpalatable \\
Salvia pratensis & Hummock with ascending stem & Well & Palatable \\
Scabiosa caucasica* & Hummock with ascending stem & Well & Palatable \\
\hline
\end{tabular}

*Temperate grasslands of the Caucasus 
Table 2. Southern European plant species

\begin{tabular}{c|c|c|c}
\hline Species & Habit & $\begin{array}{c}\text { Typical fitness in } \\
\text { current UK climate }\end{array}$ & Slug palatability \\
\hline Asphodelus lutea & Hummock with ascending stem & Intermediate & Palatable \\
Centaurea triumfettii & Hummock with ascending stem & Intermediate & Palatable \\
Centaurea orientalis & Hummock with ascending stem & Intermediate & Palatable \\
Dianthus carthusianorum & Mat with ascending stem & Intermediate & Unpalatable \\
Euphorbia nicaeensis & Hummock & Intermediate & Unpalatable \\
Hedysarum hedysaroides & Hummock & Intermediate & Palatable \\
Linum flavum & Hummock & Intermediate & Unpalatable \\
Linum narbonense & Hummock with ascending stem & Intermediate & Unpalatable \\
Lychnis coronaria & Hummock with ascending stem & Intermediate & Unpalatable \\
Lychnis flos-jovis & Mat with ascending stem & Intermediate & Unpalatable \\
Paradisea liliastrum & Hummock with ascending stem & Intermediate & Palatable \\
Salvia nemorosa & Hummock with ascending stem & Intermediate & Palatable \\
\hline
\end{tabular}

Table 3. Continental climate (mostly southern Rocky Mountain Region) plant species

\begin{tabular}{c|c|c|c}
\hline Species & Habit & $\begin{array}{c}\text { Typical fitness in } \\
\text { current UK climate }\end{array}$ & $\begin{array}{c}\text { Slug } \\
\text { palatability }\end{array}$ \\
\hline $\begin{array}{c}\text { Amsonia jonesii } \\
\text { Asclepias tuberosa (Colorado populations) }\end{array}$ & Hummock & Poor & Unpalatable \\
Balsamorhiza sagittifolius & Hummock & Poor & Palatable \\
Centaurea pulcherrima ${ }^{l}$ & Hummock with ascending stem & Poor & Palatable \\
Delphinium barbeyi & Hummock & Poor & Palatable \\
Dracocephalum grandiflorum ${ }^{2}$ & Hummock with ascending stem & Poor & Palatable \\
Geum triflorum & Mat with ascending stem & Poor & Palatable \\
Hymenoxys grandiflora & Mat with ascending stem & Poor & Unpalatable \\
Penstemon strictus & Mat with ascending stem & Poor & Palatable \\
Salvia pachyphylla & Hummock & Poor & Unpalatable \\
Sphaeralcea coccinea & Hummock & Poor & Unpalatable \\
Zinnia grandiflorus & Hummock & Poor & Unpalatable \\
\hline
\end{tabular}

${ }^{1}$ Turkey

${ }^{2}$ Kazakhstan, Central Asia

Table 4. The Sheffield mean monthly average of the temperature during 2010 to 2016

\section{MEAN MONTHLY AVERAGE TEMPERATURE}

\begin{tabular}{|c|c|c|c|c|c|c|c|c|c|c|c|}
\hline YEAR & JAN & FEB & MAR & APR & MAY & JUN & JUL & AUG & SEP & OCT & NOV \\
\hline 2010 & 1.2 & 1.9 & 5.9 & 9.1 & 10.9 & 15.2 & 16.2 & 14.9 & 13.4 & 9.5 & 49 \\
\hline 2011 & 3.9 & 6.0 & 6.6 & 120 & 12.0 & 14.2 & 15.8 & 15.8 & 14.9 & 12.2 & 8.9 \\
\hline 2012 & 5.1 & 4.5 & 8.6 & 6.7 & 11.6 & 13.4 & 15.5 & 16.2 & 12.7 & 8.8 & 6.1 \\
\hline 2013 & 34 & 2.7 & 1.7 & 7.4 & 10.6 & 14.1 & 18.4 & 16.8 & 13.3 & 11.7 & 6.2 \\
\hline 2014 & 5.0 & 5.6 & 7.4 & 10.1 & 12.2 & 15.3 & 17.9 & 14.9 & 14.4 & 11.4 & 7.8 \\
\hline 2015 & 4.1 & 3.8 & 5.9 & 9.1 & 10.6 & 13.9 & 15.7 & 15.8 & 12.2 & 10.2 & 8.7 \\
\hline 2016 & 4.8 & 4.2 & 5.5 & 7.0 & 11.8 & 14.6 & 16.6 & 16.6 & 15.4 & 10.2 & 5.4 \\
\hline
\end{tabular}


Table 5. The Sheffield mean monthly average of rain fall during 2010 to 2016

\section{MEAN MONTHLY RAINFALL}

$\begin{array}{lcccccccccccc}\text { YEAR } & \text { JAN } & \text { FEB } & \text { MAR } & \text { APR } & \text { MAY } & \text { JUN } & \text { JUL } & \text { AUG } & \text { SEP } & \text { OCT } & \text { NOV DEC } \\ 2010 & 63.7 & 64.4 & 65.0 & 28.7 & 18.1 & 45.9 & 80.6 & 49.4 & 63.5 & 69.3 & 122.4 & 31.9 \\ 2011 & 53.5 & 93.1 & 11.2 & 12.4 & 42.4 & 53.0 & 23.5 & 41.3 & 29.1 & 59.7 & 40.2 & 110.1 \\ 2012 & 82.0 & 26.8 & 30.5 & 196.6 & 47.1 & 182.3 & 118.8 & 96.0 & 102.0 & 64.3 & 116.2 & 155.1 \\ 2013 & 62.6 & 56.7 & 69.8 & 9.0 & 68.7 & 31.0 & 63.4 & 39.6 & 53.3 & 143.7 & 63.7 & 65.5 \\ 2014 & 137.5 & 106.4 & 49.0 & 63.0 & 139.5 & 49.6 & 34.3 & 92.6 & 14.4 & 87.6 & 105.4 & 96.1 \\ 2015 & 76.2 & 33.0 & 73.4 & 23.6 & 91.5 & 53.6 & 47.1 & 90.6 & 28.0 & 81.2 & 11.8 & 122.3 \\ 2016 & 99.0 & 64.7 & 95.1 & 60.8 & 64.5 & 112.5 & 31.7 & 64.6 & 38.0 & 35.5 & 107.9 & 30.5\end{array}$

The average precipitation of Sheffield during the March to September growth season during the last 50 years was used as the ambient base line during the experiments. This allowed three precipitation scenarios to be designed around the ambient value (Ambient $-50 \%$, Ambient, Ambient $+50 \%$ ) (Table 6)

Table 6. Calculation of water added to the experimental blocks (mm per month) for the rainfall scenarios based on Sheffield rainfall averages from 1955-2012

\begin{tabular}{c|c|c|c|c}
\hline Month & Average (ambient) & Ambient + 50\% & Ambient - 50\% & Mean days of rainfall \\
\hline March & 62.9 & 94.35 & 31.45 & 12.3 \\
April & 60.0 & 90 & 30 & 10.3 \\
May & 60.69 & 91.03 & 30.34 & 9.6 \\
June & 67.1 & 100.65 & 33.55 & 9.1 \\
July & 60.6 & 90.9 & 30.3 & 9.2 \\
August & 67.8 & 101.5 & 33.9 & 9.9 \\
September & 64.3 & 96.45 & 32.15 & 8.9 \\
\hline
\end{tabular}

The maximum temperature of Sheffield during the March to September growth season during the last 50 years was used as a baseline temperature upon which two temperature scenarios were designed (Temperature: Ambient and Ambient $+3{ }^{\circ} \mathrm{C}$ ). In order to achieve the desired $3{ }^{\circ} \mathrm{C}$ elevation of air temperature within the growth cabins, in a calibration study prior to the main experiment with two replications, a series of different sized vents representing; $10 \%, 15 \%, 20 \%, 30 \%, 60 \%$ of the area of the wall were cut in one of the polyethylene walls of the growth cabins. The temperature in cabins with a vent and in those with none was recorded every $30 \mathrm{~min}$ via Tinytag recorders over a one-year period. When considered in terms of both day and night temperature, a permanently open vent of $10 \%$ of the area of the wall was found to provide on average 2.6 to $3{ }^{\circ} \mathrm{C}$ difference from the ambient during the growth season.

The combination of three precipitation and two temperature scenarios led to a research design with six climate change scenarios:

a) $50 \%$ increase in precipitation (Ambient $+50 \%$ ); no change in temperature (Ambient)

b) $50 \%$ increase in precipitation (Ambient $+50 \%$ ); $3{ }^{\circ} \mathrm{C}$ increase in temperature $\left(\right.$ Ambient $+3{ }^{\circ} \mathrm{C}$ ) 
c) Ambient precipitation and ambient temperature

d) Ambient precipitation; $3{ }^{\circ} \mathrm{C}$ increase in temperature (Ambient $+3{ }^{\circ} \mathrm{C}$ )

e) $50 \%$ decrease in precipitation (Ambient $-50 \%$ ); no change in temperature (Ambient)

f) $50 \%$ decrease in precipitation (Ambient $-50 \%$ ); $3{ }^{\circ} \mathrm{C}$ increasing in temperature (Ambient $+3{ }^{\circ} \mathrm{C}$ )

In all treatments (ambient, ambient \pm 50 ) all growth cabins were covered with a transparent polythene $(1.3 \times 1.0 \times 1.0 \mathrm{~m})$, to exclude natural rainfall from the plots to allow the scenarios to be achieved by carefully controlled irrigation.

In the case of the ambient treatments growth cabins had a polythene cover on the roof. For example, The average precipitation in Sheffield during March over the last 50 years was $62.3 \mathrm{~mm}$ and the average number of rainfall days during the same time were 12, equating to a rainfall event approximately 3 times per week. Ambient precipitation treatment plots were therefore irrigated 3 times a week and each time they received $5.0 \mathrm{~mm}$ of water $/ \mathrm{m}^{2}$ during March. For the plots with other precipitation treatments $(-50 \%$ or $+50 \%)$, this amount of water was increased or decreased in relation to the value of $5.0 \mathrm{~mm}$ at each irrigation event ( Table 4).

Seeds of the 36 species were sown in seedling trays in April 2012 in a greenhouse and a growth cabinet. Before seed sowing, those species which needed a period of chilling to germinate were pre-chilled in small pots of moist compost in a fridge at $2{ }^{\circ} \mathrm{C}$ for varying durations to ensure that their chilling requirements were sufficiently satisfied to achieve uniform germination in the experiment. The species with hard seed coats were scarified. After seeds had emerged and were well established, the seedling trays and pots were transferred outside of the greenhouse to harden them off. Seedlings were transplanted into the experimental plots, which were covered with $75 \mathrm{~mm}$ deep mulch layer of sand from June 2012. Four seedlings of each species (144 seedlings in total) were planted randomly in each $1 \mathrm{~m} \times 1.30 \mathrm{~m}$ treatment plots (Fig. 1).

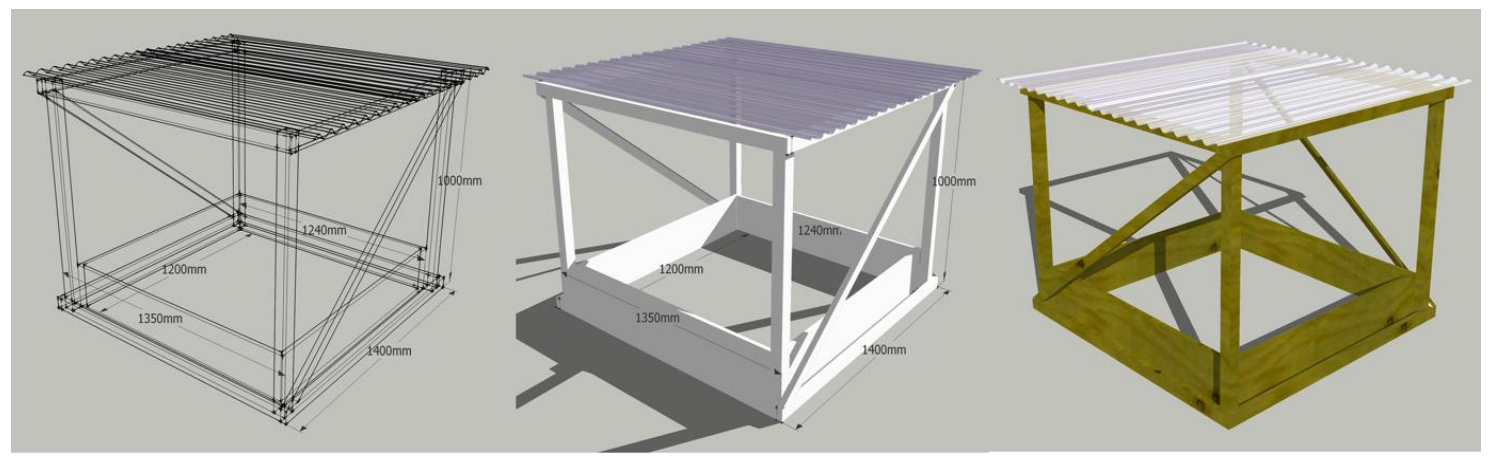

Figure 1. The dimensions of plots and climate control chambers

The purpose of the experiments was to create two areas with different densities of molluscs, low and higher. In order to achieve this aim and evaluate the above objectives, it was necessary to provide two experimental blocks. The mollusc was involved to one of the blocks and the other block was kept as free or low-density mollusc area (Fig. 2). 


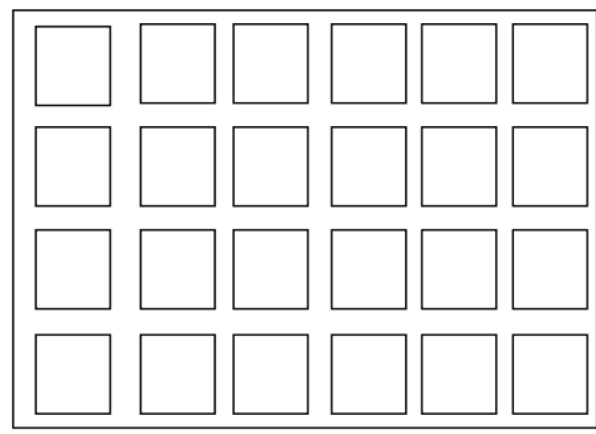

Low mollusc area

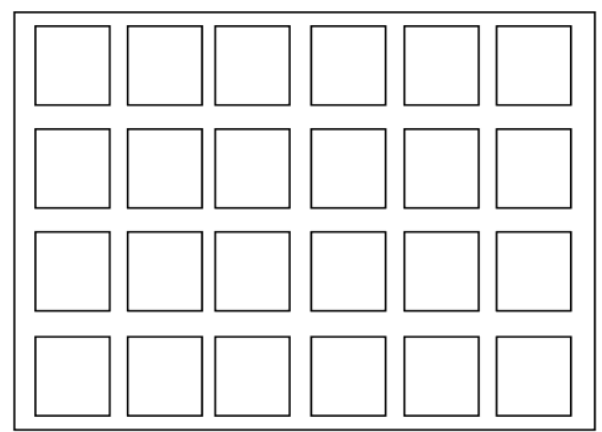

Mollusc friendly area

Figure 2. The layout plan of the research area and the mollusc friendly and non mollusc blocks

In mollusc friendly area, to provide a desirable place for mollusc grazing, a combination of cat food was offered to the slugs on saucers that also contained garden soil and was covered with a black film. These saucers were then used to inoculate the most intense mollusc feeding in mollusc friendly block (half of the experiment) (Figs. 3-7).

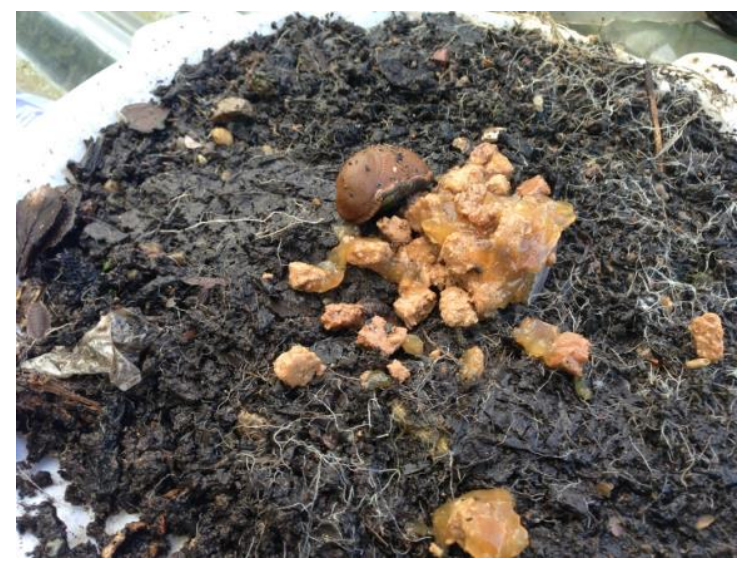

Figure 3. Adding cat food to the slug's shelter; cat food is very palatable to slugs

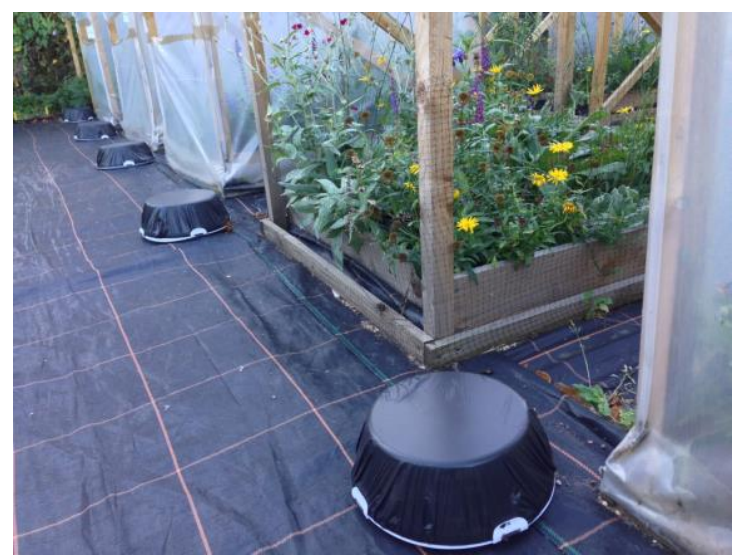

Figure 4. The slug shelter covered with black film and were added to the mollusc friendly area. At first next to the plots and later inside them. Slug availability was checked every day during early spring and late summer 


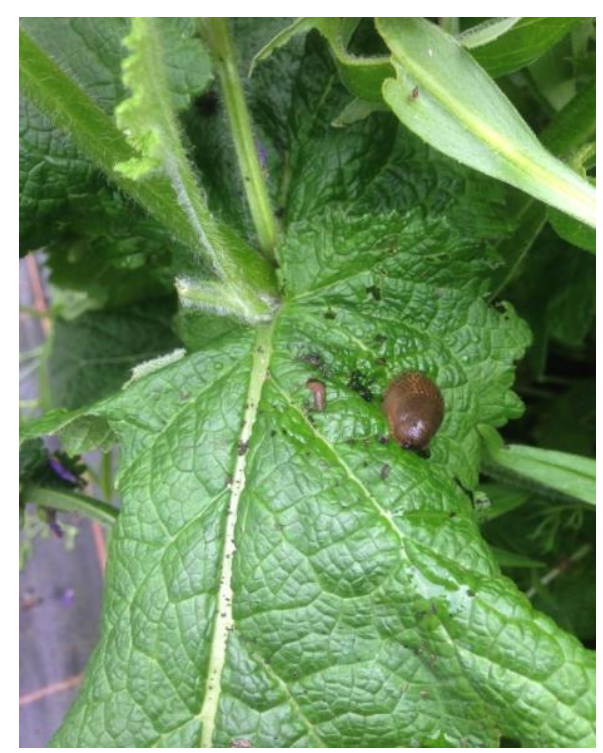

Figure 5. Salvia nemorosa is palatable to slugs and snails

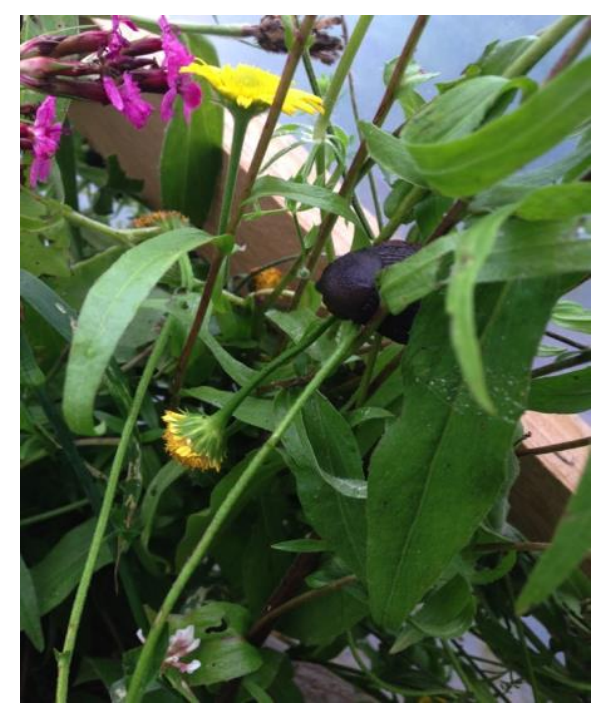

Figure 6. Slug grazing on Bupthalmum salicifolium

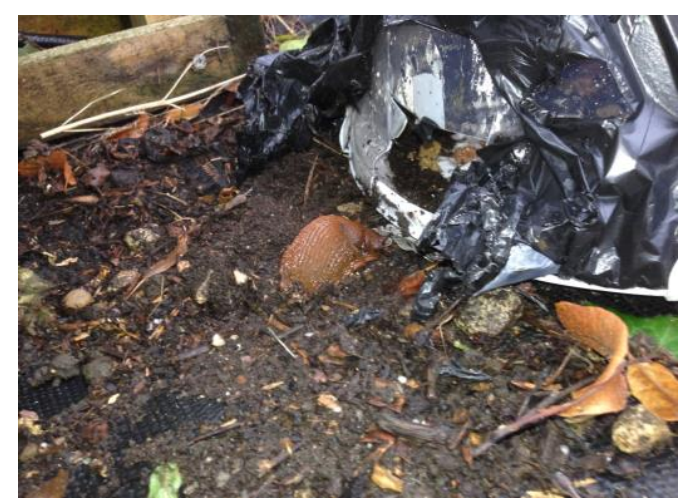

Figure 7. During the night, the slugs feeding from the species of plots and in the morning they come bake to the shelter 


\section{Data collection and data analysis}

The productivity of plant species within each plot was recorded from spring 2013 to autumn 2014. The number of plants of each species in each plot was counted every two-weeks to get the percentage of individual species that disappeared during the observation period. The plants were harvested in October 2013 after the first growing season. A harvesting procedure was developed to cope with highly variable biomass and species of very different sizes within an individual plot and plant groups, and also to ensure that all plant samples were available for harvest at the end of the summer. Each of the sampled plant species from all species were cut off at a ground level and the cut biomass of each individual plant placed into individual coded envelopes. Samples were dried at ambient temperatures $\left(15-25^{\circ} \mathrm{C}\right)$ within a botanical garden greenhouse before being transferred to the oven at $60{ }^{\circ} \mathrm{C}$ for five days. A similar protocol was utilized in November 2014 after the second growth season.

Each of the lower and higher mollusc density blocks was subdivided into 24 subplots (48 subplots in total). The subplots represented the six treatments with four replications inside of each block. The non-completely random, directed blocking approached used in this experiment was based on statistical advice to reduce shade effects from the tree and hedges near the plots. Cumulative dry mass of the different harvests in one year was used for data analysis. The Shannon-Wiener index and Shannon evenness (Magurran, 1996) were calculated based on biomass data for the species in the first year, and based on the cover values obtained for the next years. The following equations were used:

$$
\begin{gathered}
\text { Shannon-Wiener index: } \mathrm{H}^{\prime}=-\sum_{\mathrm{i}=1}^{\mathrm{S}} \mathrm{P}_{\mathrm{i}} * \mathbb{P}_{\mathrm{i}} \\
\text { Shannon evenness: } \mathrm{E}^{\prime}=\mathrm{H} / \mathrm{ln} \mathrm{S}
\end{gathered}
$$

where $\mathrm{p}$ is the biomass of species (first year) or cover (third year) and $\mathrm{S}$ is the number of species.

Statistical analysis was undertaken using SPSS and also Minitab for Mac. Data was initially explored through a variety of statistical approaches, both parametric and non-parametric. This included transformation $\log$ e for weight data, and arcsine square root for percentage data to improve the properties of the data sets for parametric analysis, namely distributional characterizes and homogeneity of variance (Zar, 1999).

\section{Results}

The effects of different climate scenarios on a community of three ecological groups of species in the absence of molluscs were investigated by Alizadeh (2016). In this research, the effects of mollusc grazing on plant communities, under different climate scenarios has been studied. In all the figures overlapping SE bars indicate that, the difference between the two means is not statistically significant $(\mathrm{P}>0.05)$. In all graphs the mean of biomass is represented for the two years of the study. 


\section{Comparison of mollusc grazed and non-mollusc grazed communities}

\section{Effects of molluscs on the total biomass of the communities}

The graph in Figure 8 suggests that the overall biomass of a community of well fitted species is not greatly influenced by mollusc grazing, where as the intermediate fitted species are much more affected, ie as a group are much more palatable. There is no difference for poorly fitted species (Fig. 8).

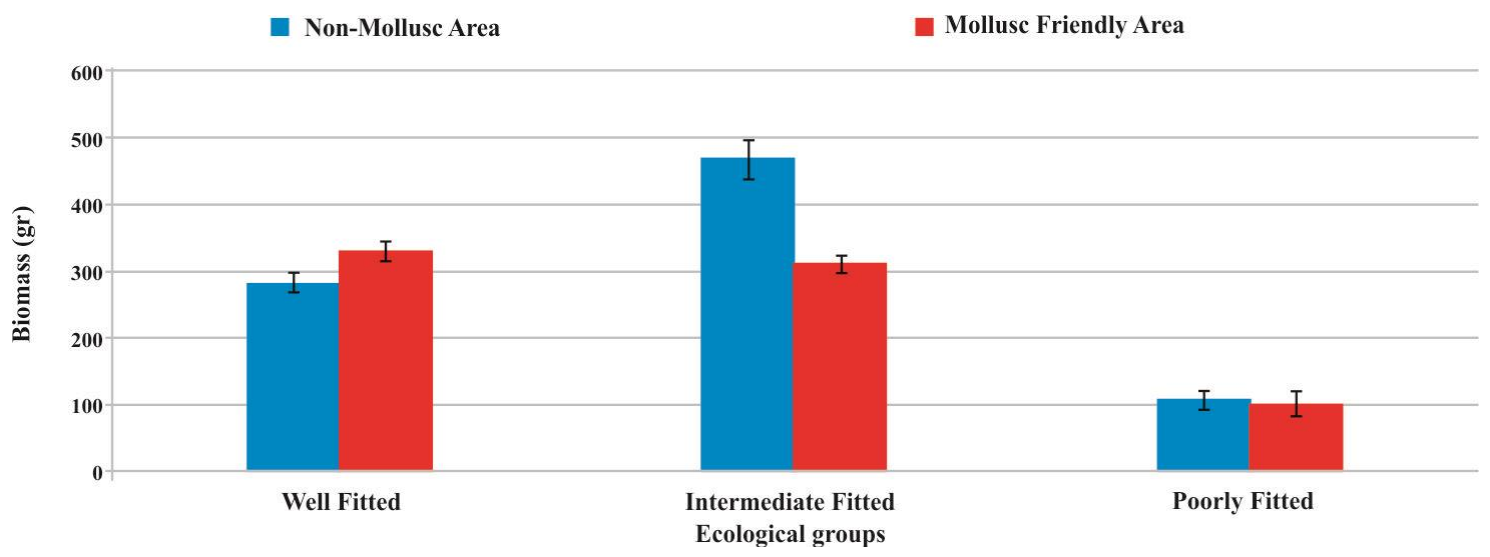

Figure 8. The effects of mollusc grazing on overall biomass production of different fitness groups

Effects of molluscs on the total biomass of the communities at different moisture regimes

The difference between -mollusc and + mollusc treatments are not very notable for the well and poorly fitted groups. For the poorly fitted group the main factor is clearly inability to tolerant elevated moisture, rather than slug grazing. Within the well fitted group there is a step wise progression in biomass as one moves from $-50 \%$ to $+50 \%$. It is clear that the molluscs are not causing the biomass to decline below that of the communities with no mollusc treatment as soil moisture increases. This suggests that positive benefits of more water on biomass production are greater than the negative effects of molluscs on consuming that biomass. This is perhaps different to what might be expected: wetter conditions allow longer mollusc grazing and hypothetically greater consumption of plant biomass. The intermediate fitted group clearly shows the effects of mollusc grazing most strongly with biomass productivity of these species much higher when molluscs are excluded, and much less when present (Fig. 9).

Effects of molluscs on the total biomass of the communities at different temperature regimes

Increasing the temperature levels improves the biomass productivity of all the species in all ecological groups whether molluscs are present or not. In the most responsive group (the intermediate group) the molluscs do however appear to apply a break to biomass production as temperature rises, perhaps because molluscs are more active at these elevated temperatures.

In well-fitted species the biomass productivity in the mollusc area at both temperatures were more than that in the non-mollusc areas. The actual differences are 
very small, reinforcing the fact that molluscs did not have a great deal of impact on these well fitted species (Fig. 10).

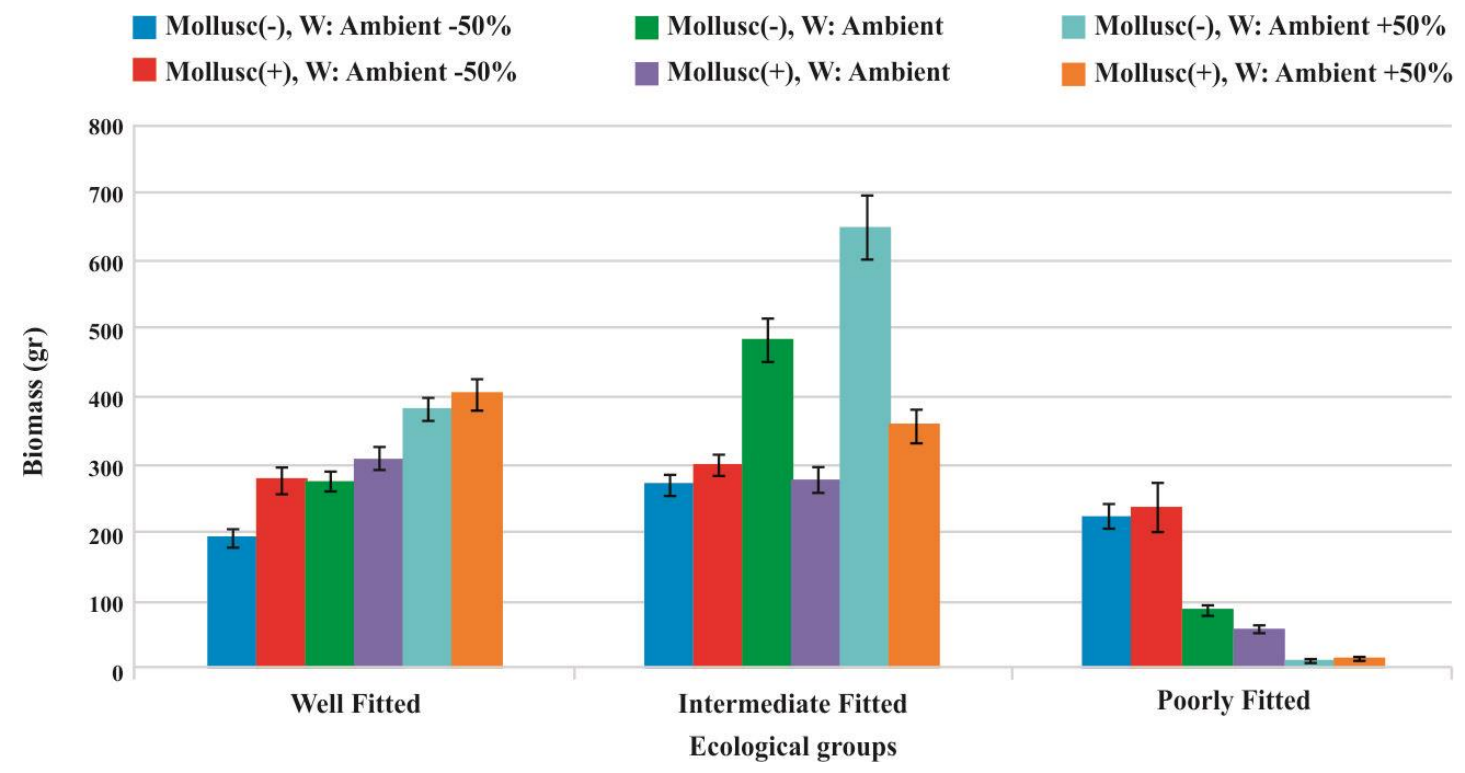

Figure 9. Comparison of mollusc grazed area and non mollusc area - the effects of mollusc grazing and moisture availability on biomass production of the studied species within the different group

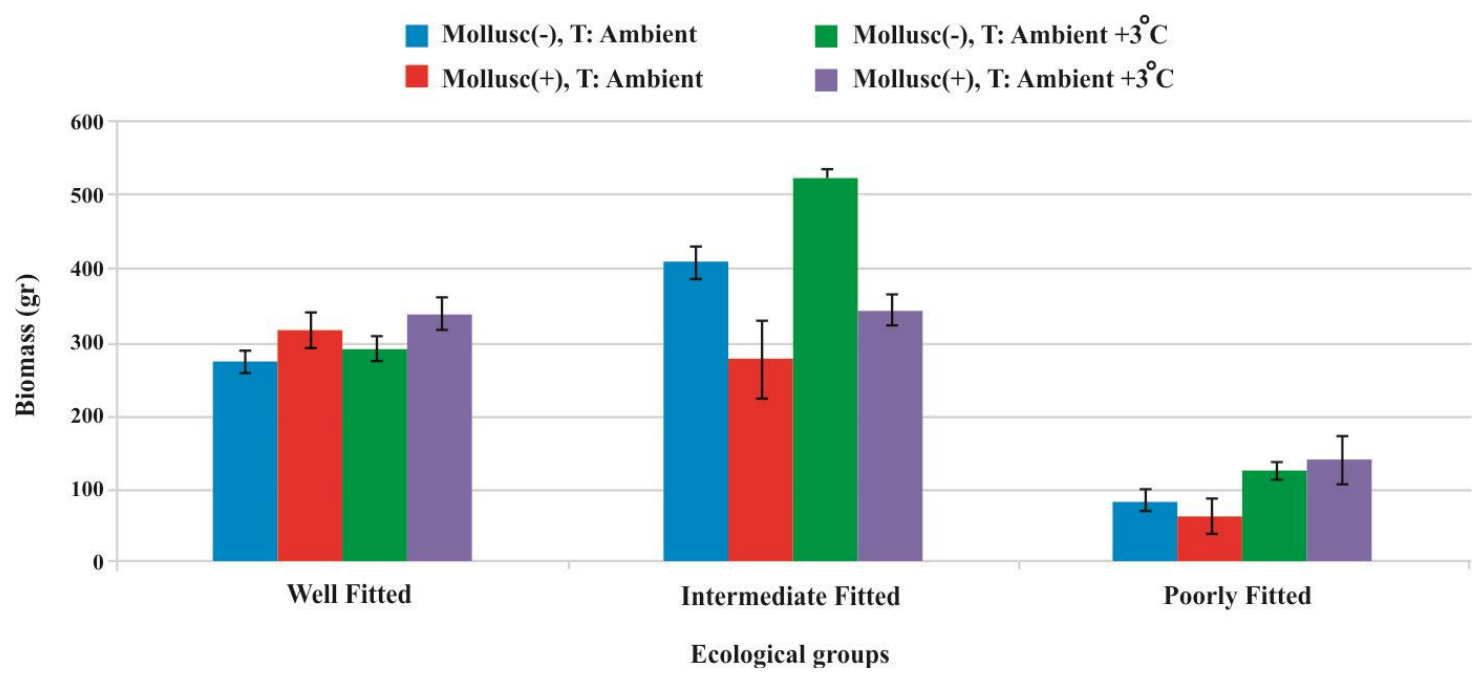

Figure 10. This figure shows how biomass production of the studied species has been affected in non-mollusc and mollusc friendly area as a result of variation in the temperature treatments

Effects of molluscs on the total biomass of the communities at different temperature and moisture regimes

The graph in Figure 11 compares how mollusc grazing can be affected by the combination of the water and temperature treatments. The overall pattern is similar to what was observed in the previous graphs. The main effects are seen in the intermediate fitted group where the presence of molluscs has a significant reduction in total biomass, 
compared to when absent, and this pattern is generally repeated across all climatic comparisons. The effect of the molluscs on the fitted species is rarely significant, suggesting that the species chosen are either fundamentally less palatable to molluscs, or that the least palatable species in the mix were able to utilize the increased resources made available by damage to the more palatable species. This process does not seem to be able to operate in the intermediate species. Normally slugs and snails do not show activity at drier and warmer conditions (w: Ambient $-50 \%$ ). So the mass production of species at these climate conditions is not caused by the mollusc activities. Also the results indicated that the poorly fitted species cannot survive under wetter condition (w: Ambient $+50 \%$ ). In this situation biomass productivity of species in both blocks (mollusc grazed and non-mollusc area) did not show significant difference. As explained before, for the well fitted group mollusc presence reduce the competition between species (Fig. 11).

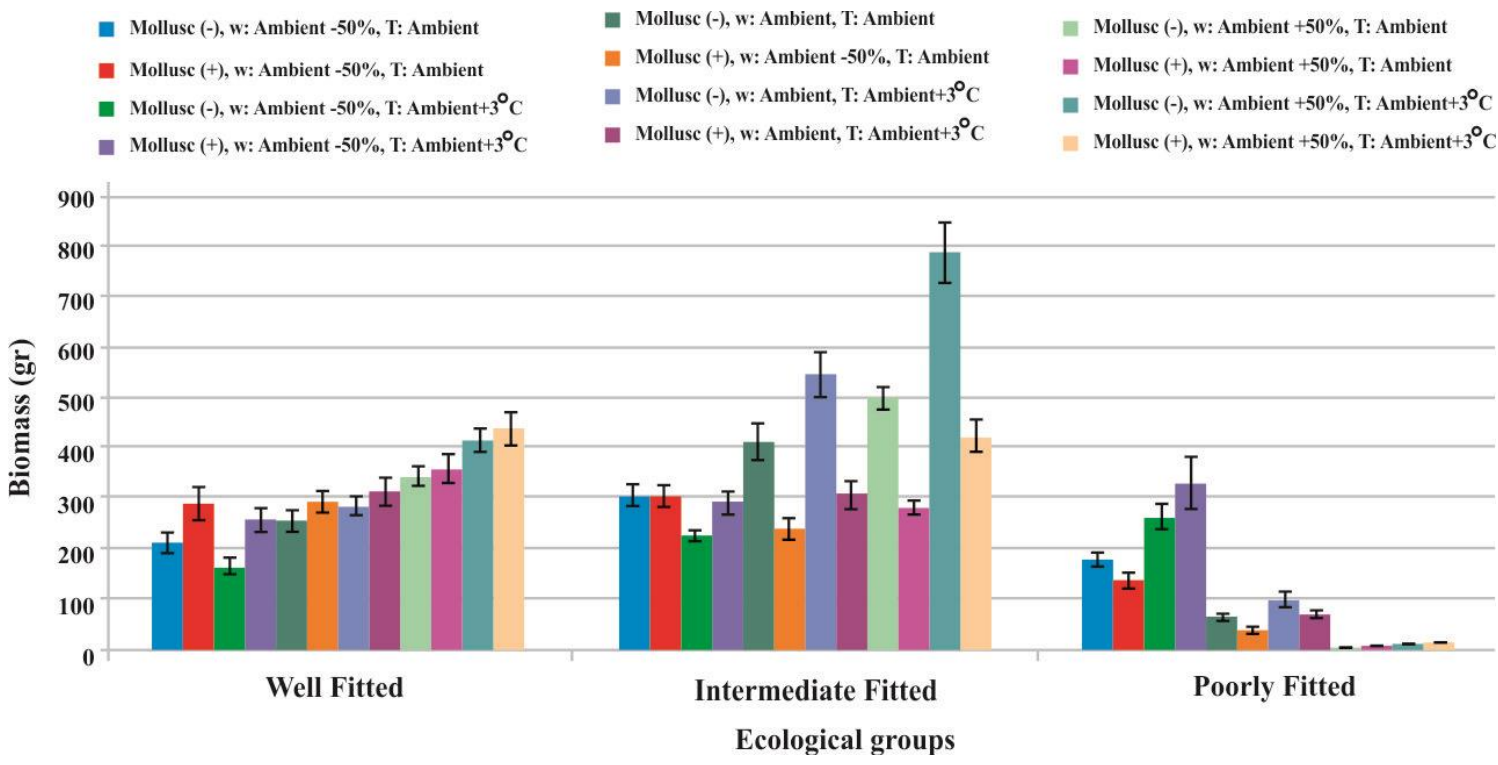

Figure 11. The effects of mollusc grazing on biomass of species under different levels of moisture and temperature

The effect of mollusc grazing on individual plant species with the well fitted and intermediate fitted species

The effects of mollusc grazing on well fitted species and intermediate fitted species are evaluated in this section. As it was not clear that palatable species in poorly fitted species disappeared as a result of mollusc grazing or the climate condition, the poorly fitted species are not compared.

\section{Effects of molluscs on the total biomass of the well fitted species}

The biomass productivity of the well-fitted species under mollusc grazing condition is compared with the mass productivity of non mollusc area and shown in the graph in Figure 12. As seen clearly, the most palatable species in these group, Arnica montana, Phyteuma spicatum, Salvia pratense and Scabiosa caucasica show much lower biomass when they are exposed to mollusc grazing. The unpalatable species, Galium verum, Geranium sylvaticum, Knautia arvensis, Origanum vulgare 
and Prunella vulgaris on the other hand show even higher biomass production. Although Bupthalmum salicifolium and Centaurea montana were included as palatable species on the basis of experience in previous studies, at present of the other palatable species they behaved as non-palatable, in this study. The molluscs preferred to feed on others (Fig. 12).

Effects of molluscs on the total biomass of the well fitted species at different moisture regimes

The effects of mollusc grazing on the biomass productivity of the well fitted species when exposed to the moisture treatments and condition is shown in the graph in Figure 13. The general pattern here mirrors what was shown in previous graphs of total biomass. In general, biomass increases as water increases; the greater opportunities for slugs to be active does not prevent this occurring except in the most palatable species. In the case of Arnica, Phyteuma, Salvia and Scabiosa, these species disappear at ambient and ambient plus $50 \%$ water treatments.

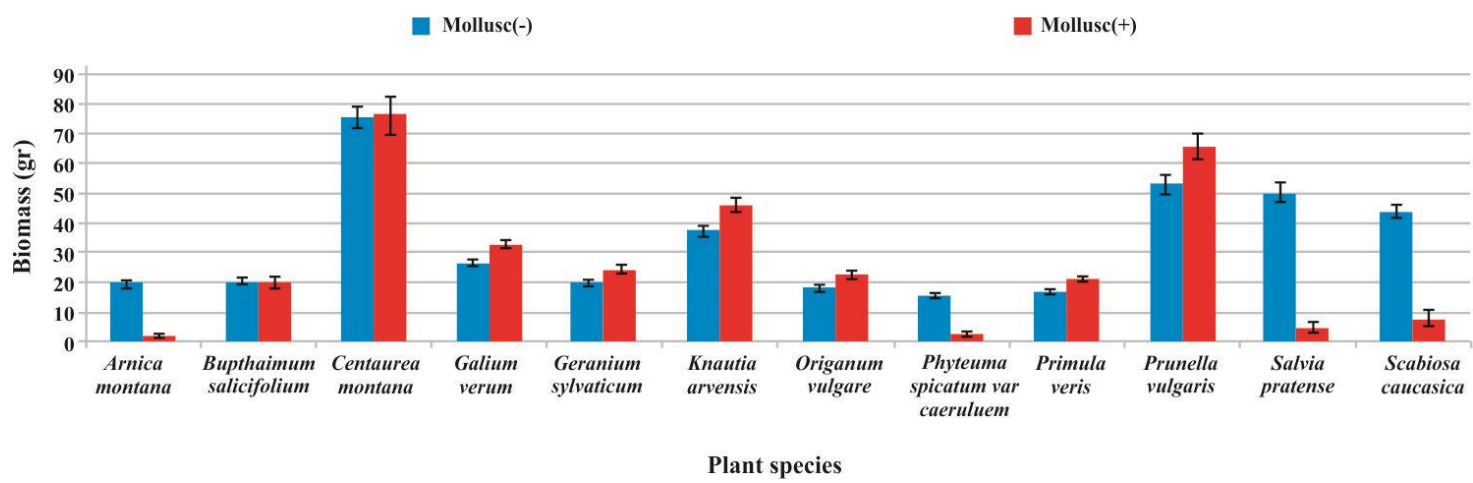

Figure 12. The effects of mollusc grazing on total biomass of well fitted species

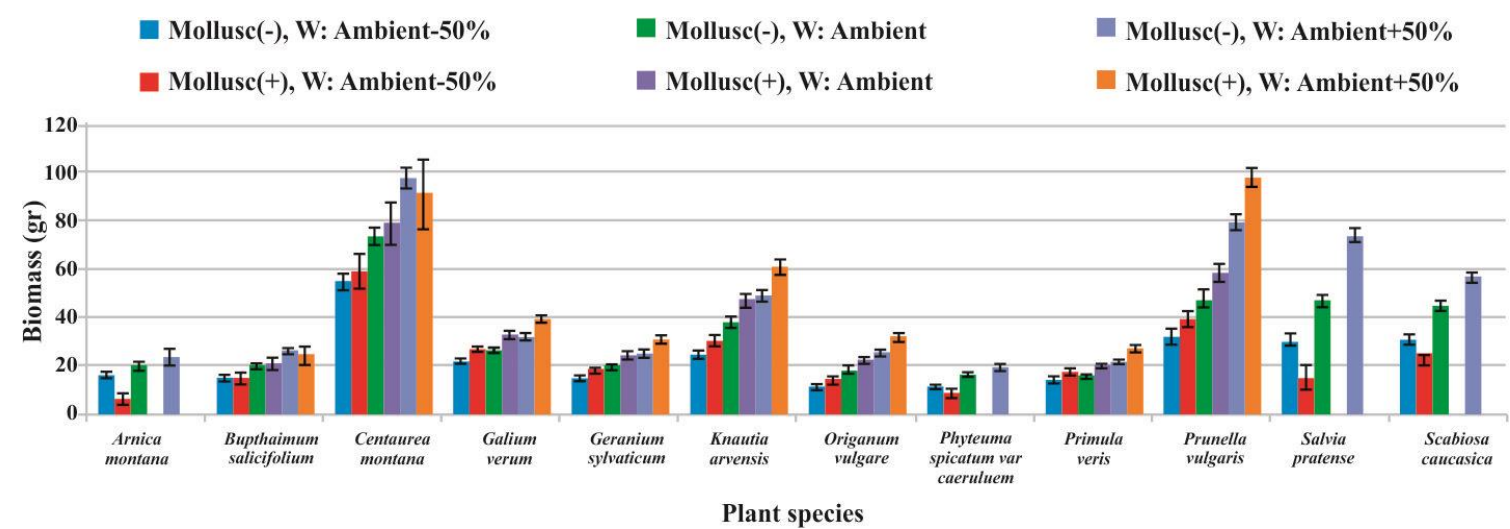

Figure 13. Comparison of mollusc grazed area and non-mollusc area- the effects of mollusc grazing on biomass productivity of well fitted species under different levels of moisture availability

It is clear that molluscs do not have activity when we have Ambient - 50\% moisture level and showed their maximum at Ambient $+50 \%$. Palatable species in these group (Arnica montana, Phyteuma spicatum, Salvia partense and Scabiosa caucasia) show 
much lower biomass presence when they are exposed to mollusc grazing. In these species we see some degree of biomass presence when we have Ambient - 50\% moisture level. This is due to lower activities of molluscs in drier environments. The unpalatable species; (Bupthalmum salicifolium, Centaurea montana Galium verum, Geranium sylvaticum, Knautia arvensis, Origanum vulgare and Prunella) however show more biomass with increasing moisture levels (Fig. 13).

The effects of molluscs on the total biomass of the well fitted species at different temperature regimes

As the graph in Figure 14 shows clearly, increasing the temperature $\left(3^{\circ} \mathrm{C}\right)$ does not make a significant effect on growth and development of well-fitted species. The same patterns of reductions in the biomass of the palatable species are shown as in previous graphs, irrespective of temperature. The graph indicates that increasing the temperature has negative effects on mollusc activity and the biomass productivity of palatable species at ambient level of temperature is less than ambient $+3{ }^{\circ} \mathrm{C}$ (because of more mollusc activity) (Fig. 14).

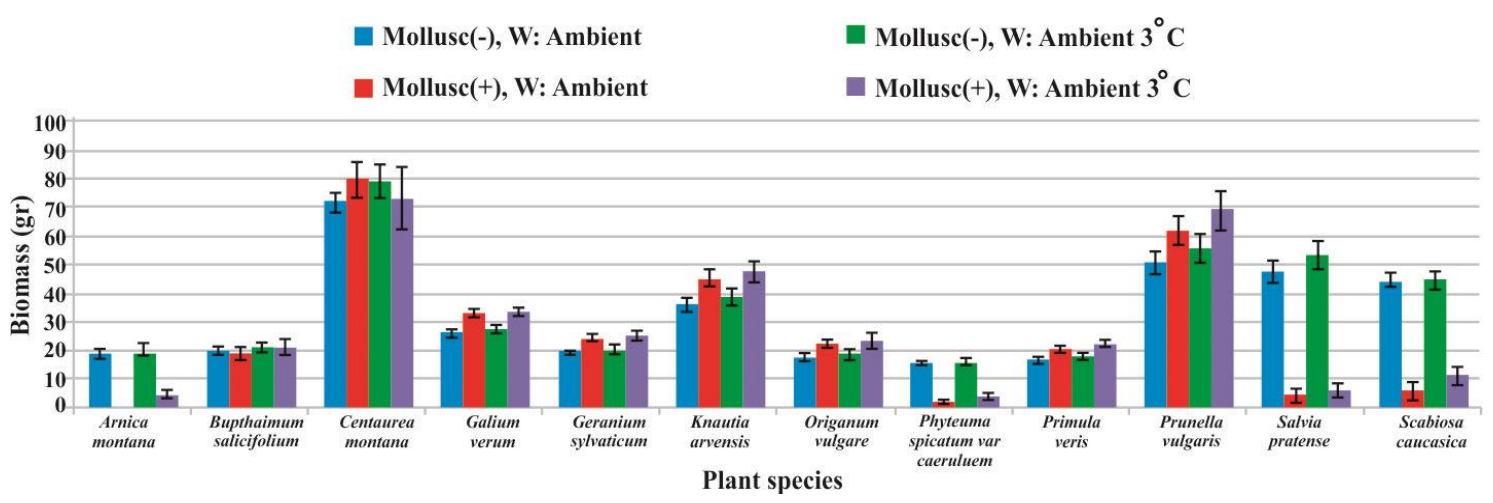

Figure 14. The effects of mollusc grazing on biomass productivity of well fitted species under different levels of temperature

Effects of molluscs on the total biomass of the well fitted species at different temperature and moisture regimes

The graph in Figure 15 shows that combined effects of higher moisture and temperature, provided more desirable environment for mollusc activity and all the palatable species disappeared in this climate (Ambient $+50 \%$ and Ambient $+3{ }^{\circ} \mathrm{C}$ ), but mirrors the trends previously shown in response to temperature and moisture as individual factors. This kind of climate leads the non-palatable species to produce more biomass not only because the climate condition, but also because the mollusc activity. Some species such as Arnica montana are very palatable for molluscs. They disappeared even at Ambient - 50\% of water regime and ambient level of temperature (Fig. 15). 


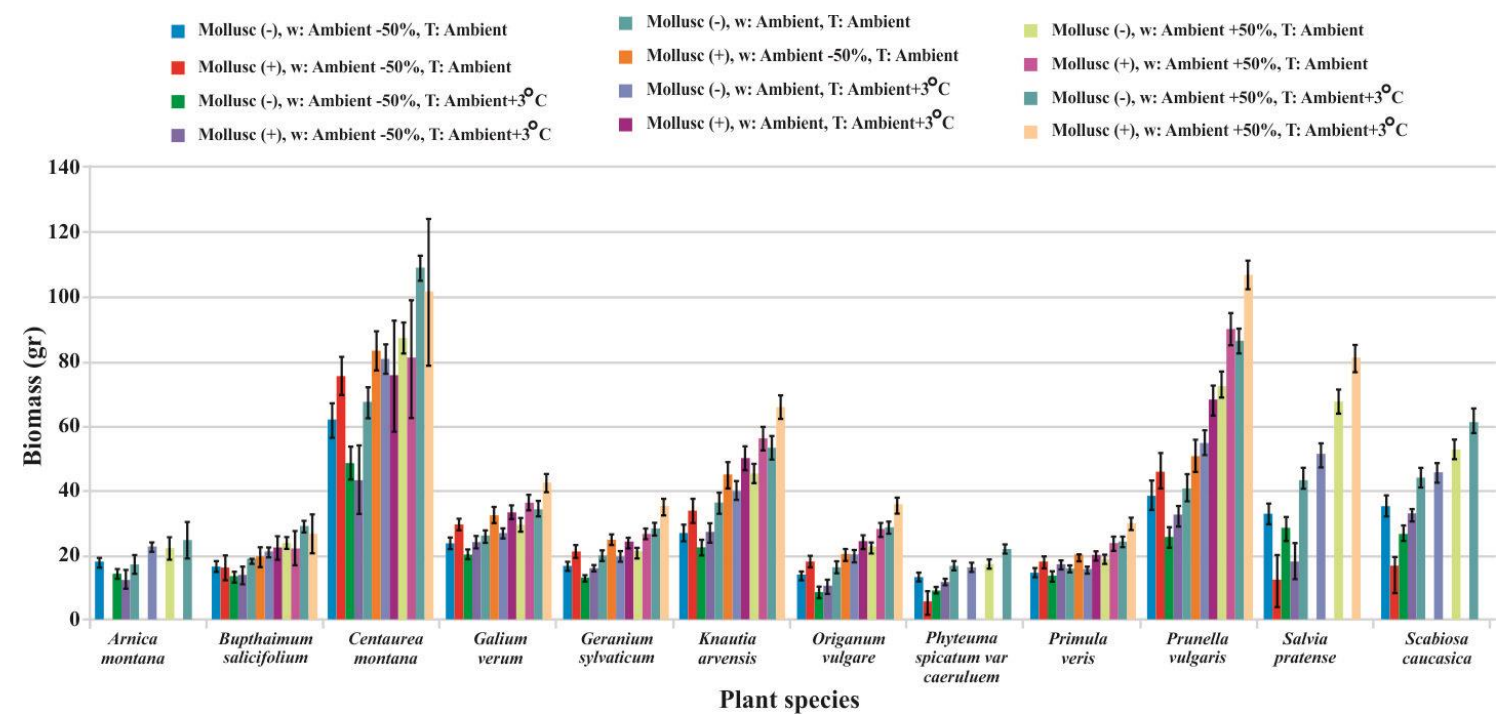

Figure 15. The effects of mollusc grazing on biomass productivity of well fitted species under different levels of moisture and temperature

\section{Effects of molluscs on the total biomass of the intermediate fitted species}

The biomass productivity of the intermediate fitted species under mollusc grazing condition is shown in the graph in Figure 16. The unpalatable species; Dianthus carthusianorum, Euphorbia nicaensis, Linum flavum 'Compactum', Linum narbonennse, Lychnis cornonoria and Lychnis flos-jovis show increased biomass production, for the same reasons as previously proposed for fitted species. This can be attributed to the role of mollusc grazing. Unpalatable species show higher growth and mass productivity in mollusc friendly area. One reason can be more space for growth and reducing the competition for light, water and nutrition. The palatable species in these group Asphodeline lutea, Centaurea triumfetii, Centaurea orientalis, Hedysarum hedysaroides, Paradisea liliastrum and Salvia nemorosa show much lower biomass presence when they are exposed to mollusc grazing. Hedysarum appears to be the most palatable species on the basis of grazed biomass as a percentage of non-grazed biomass (Fig. 16).

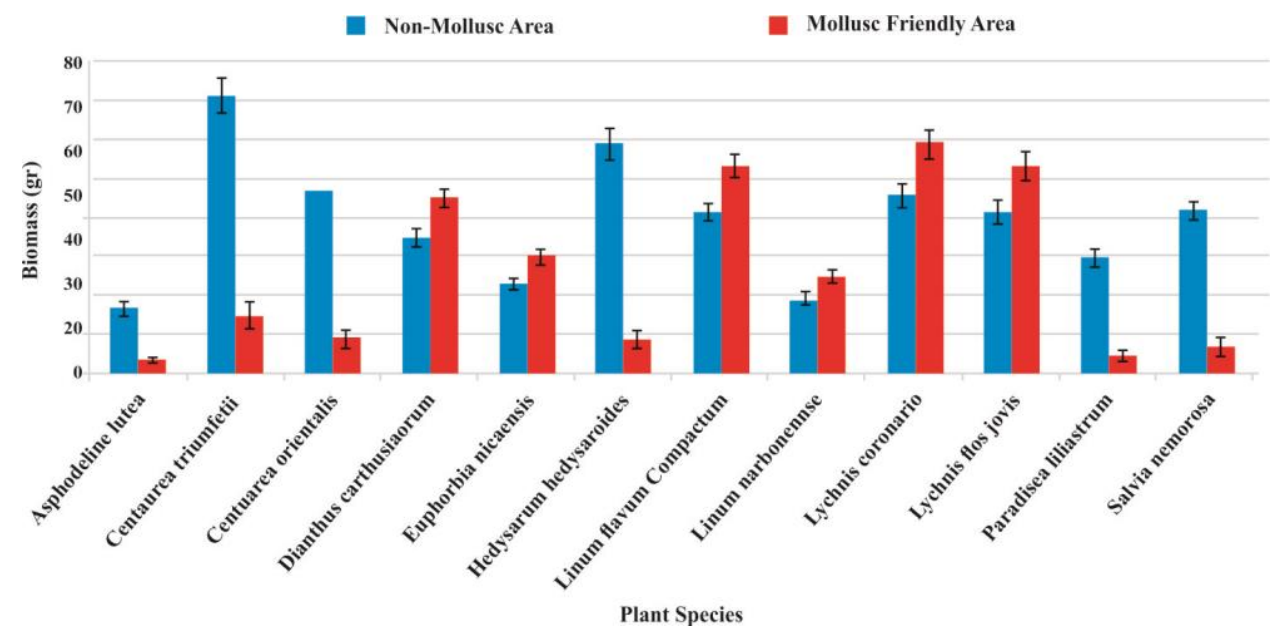

Figure 16. The effects of mollusc grazing on total biomass productivity of intermediate fitted species 
Effects of molluscs on the total biomass of the intermediate fitted species at different moisture regimes

The biomass productivity of the intermediate fitted species when exposed to the moisture treatments and under mollusc grazing condition is shown in the graph in Figure 17. Biomass increases step wise in intermediated fitted species as water increases except in the case of palatable species which are severely damaged or eliminated at these higher moisture levels. The palatable species in these group (Asphodeline lutea, Centaurea triumfetii, Centaurea orientali, Hedysarum hedysaroides, Paradisea liliastrum, Salvia nemorosa) show much lower biomass presence when they are exposed to mollusc grazing. So due to lower activities of mollusc in drier environments the differences between mass productivity of species between non mollusc area and mollusc grazed area may refer to the other factors. The unpalatable species, Dianthus carthusinorum, Euphorbia nicaensis, Linum flavum Compactum, Linum narbonennse, Lychnis cornonoria, Lychnis flos jovis, however, show more biomass with increasing moisture levels (Fig. 17).

Effects of molluscs on the total biomass of the intermediate fitted species at different temperature regimes

The general pattern for biomass is to increase with an increase in temperature. Higher temperature and drier environments potentially hamper mollusc activity, however in the case of the palatable species in the graph in Figure 18 there is no compelling evidence that higher temperature has this effect. All of the palatable species in the intermediate fitted group (Asphodeline lutea, Centaurea triumfetii, Centaurea orientali, Hedysarum hedysaroides, Paradisea liliastrum, Salvia nemorosa) have produced sharply less biomass under mollusc friendly area condition. The higher temperature treatment leads to more biomass productivity for these species under non-mollusc grazing condition. Not a notable difference is observed between the produced biomass in mollusc friendly environment between the two temperature treatments, that though the mollusc grazing is less but overall they are active enough to consume the produced biomass under the higher temperature treatment. The unpalatable species; (Dianthus carthusinorum, Euphorbia nicaensis, Linum flavum Compactum, Linum narbonennse, Lychnis cornonoria and Lychnis flos jovis) however show slightly more biomass with increasing the temperature levels (Fig. 18).

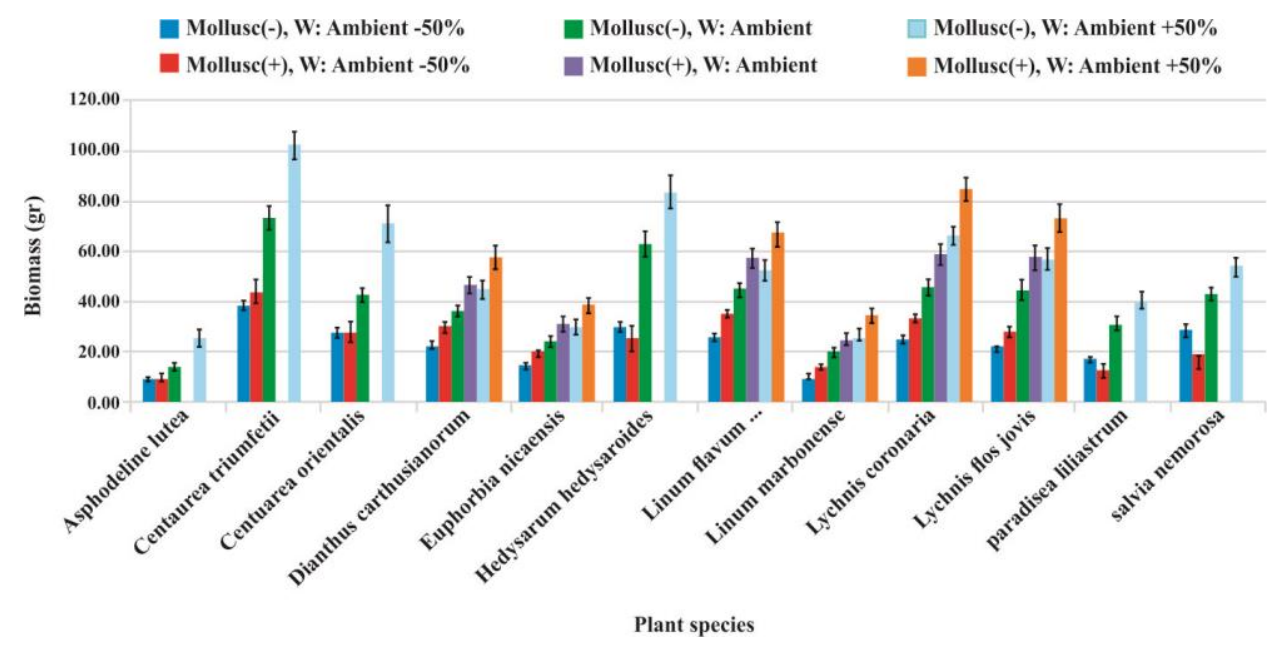

Figure 17. The effects of mollusc grazing on biomass productivity of intermediate fitted species under different levels of moisture 


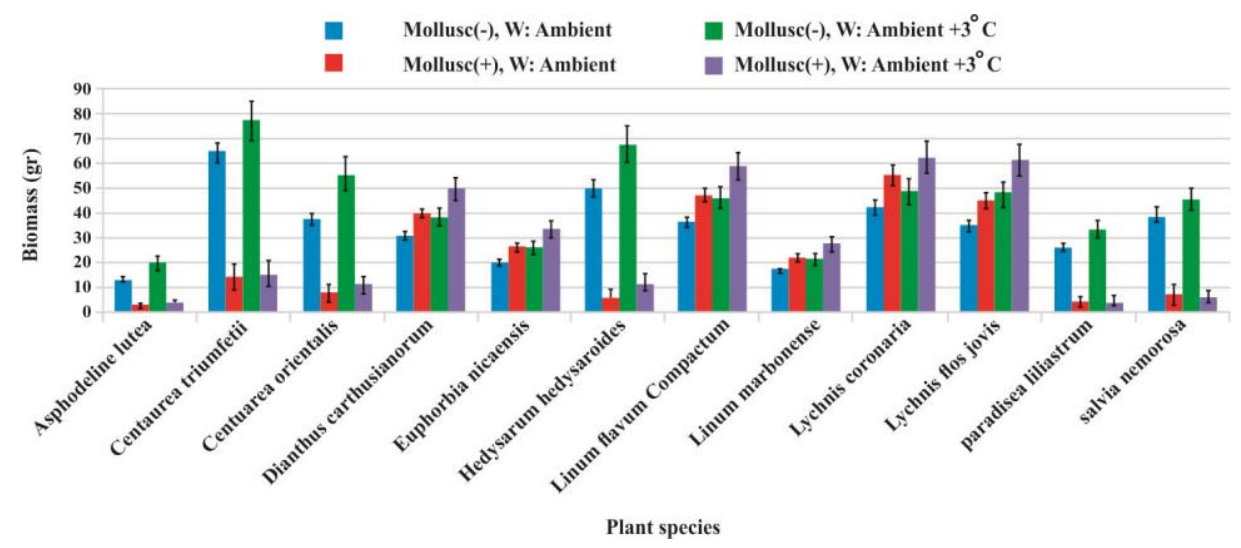

Figure 18. The effects of mollusc grazing on biomass productivity of intermediate fitted species under different levels of temperature

Effects of molluscs on the total biomass of the intermediate fitted species at different temperature and moisture regimes

The data for the different treatment combinations of water, temperature with and without mollusc grazing, follow the same patterns as the previously shown graphs, i.e. there is a net increase in biomass as temperature and water increase but this is reversed in the presence of molluscs in the case of palatable species. Increasing the temperature do not show significant effect in mollusc grazing in intermediate fitted species. Because palatable species disappeared in both levels of temperature in ambient and Ambient $+50 \%$ of moisture availability. Comparison of non mollusc area and mollusc grazed area show that in the presence of mollusc grazing, unpalatable species growth is increased more and more mass is produced. For example, Lychnis coronaria at in mollusc grazed area and at Ambient $+50 \%$ of moisture and Ambient $+3{ }^{\circ} \mathrm{C}$ of temperature produced $26 \%$ more biomass than the same treatment in non mollusc area (Fig. 19).

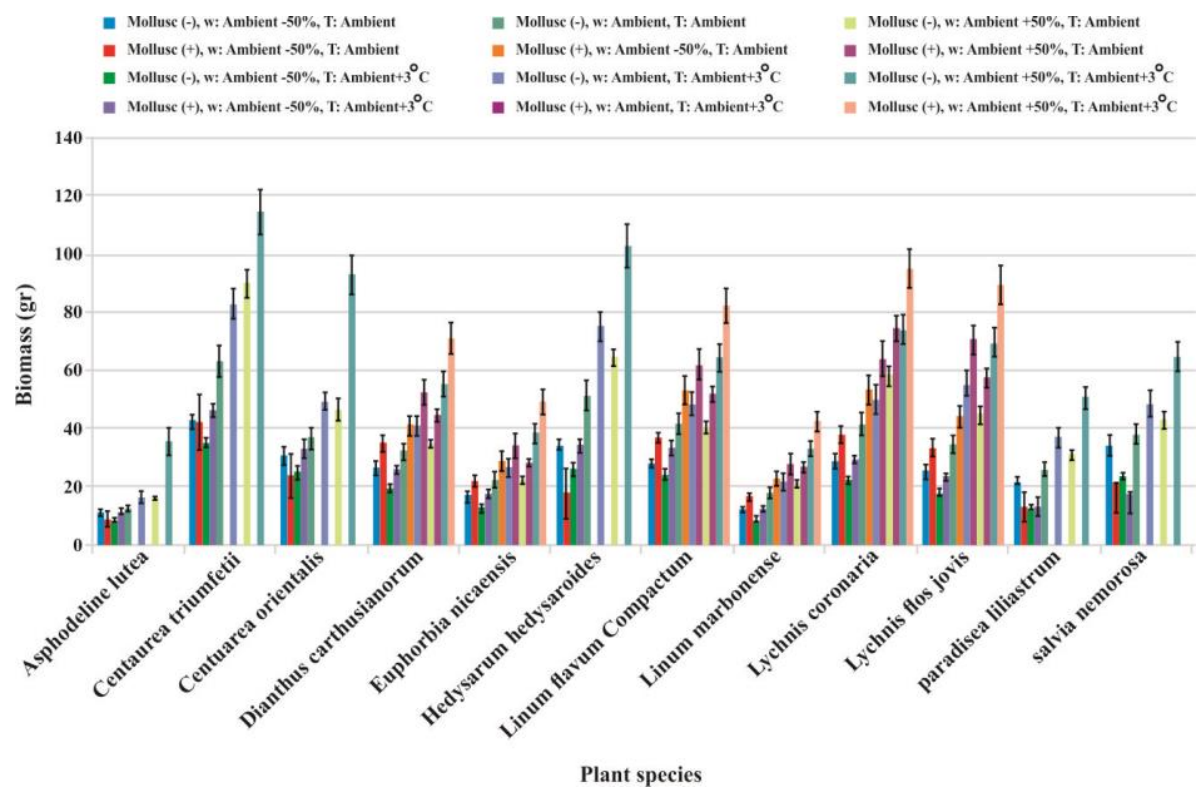

Figure 19. The effects of mollusc grazing on biomass productivity of intermediate fitted species under different levels of moisture and temperature 


\section{Discussion}

Climate change affects all parts of an ecosystem. Greenspace and greenspace's biodiversity as a part of the urban ecosystem will be affected by climate change. So, in this study, the responses of slugs and snails to the different climate change scenarios in a designed plant community were investigated. This study aimed to investigate how mollusc grazing and environmental conditions (water and temperature) affect the biomass productivity among different plant species. We are aware that the majority of ecosystem services are affected by invertebrates in some ways (Prather et al., 2013), though studies that investigate the relationships between climate change-related responses by invertebrate to ecosystem services consequences are somewhat limited.

Mollusc behaviour and impacts on ecosystems under climate change scenarios are not thoroughly studied; nevertheless, previous studies provide a general understanding about climate change impacts on slug herbivory (e.g., Hitchmough and Wagner, 2011; Frank, 2003; Briner and Frank, 1998; Fenner et al., 1999; Keller et al., 1999; Scheidel and Bruelheide, 1999; Hulme, 1994). For instance, the role of moisture on mollusc grazing activities is well established. Nystrand and Granstroom (1997) showed that the activities of soft body animals are highly related to available moisture levels. When the soil moisture is reduced, and bodies of these animals face desiccation, their feeding activity is significantly hampered.

For each of the three ecological groups studied in this research, six palatable and six unpalatable plant species were exposed to mollusc activities. As mentioned earlier, when the growth conditions were favourable and adequate moisture for mollusc grazing was provided, mollusc grazing significantly reduced the level of biomass for palatable species. Interestingly, unpalatable plant species, due to low competition, showed more biomass productivity in mollusc friendly environments. This scenario may lead to the dominance of the most unpalatable and productive species. Moisture and temperature are not the only factors that affect plant consumption by molluscs. As the study of Hithmough and Wagner (2011) suggest, the effect of mollusc grazing on palatable species also depends on the physical size and growth rate of the seedlings. For instance, palatable species with slow growth or small seedlings are typically more likely to be eliminated due to mollusc grazing. They also conclude that mollusc grazing can affect the population and community dynamics of plant species. Scheidel and Bruelheide (1999) research reveals that mollusc feeding behaviour even depends on morphological factors. For instance, epidermal cell thickness and hairiness of a plant's leaves are affected if molluscs prefer them.

\section{Molluscan herbivory, designed plant community, individual species and climate change}

The results showed that increasing moisture levels improve mollusc activities and also the plant growth and, on the other hand higher temperature reduces mollusc activity. Non-palatable species produced more dry mass in mollusc friendly area than in non mollusc area because of low competition. The graph indicates that slugs and snails select their food from palatable species. This is presumed to be because grazing is either acting as a stimulus to produce more biomass, rather like a form of light pruning, or more likely, because damage to the more palatable species is freeing up resources which they can use to increase their own biomass. Thus, reduced competition and access to 
more favorable environment as a result of deleting the palatable species by mollusc grazing, is the key reason of the increasing biomass production of unpalatable species.

The results indicated that molluscan herbivory interactions with climate change affected the stability of both individual species and the plant community. The results also confirm the findings of the previous researchers, such as Vorosmarty and Sahagian (2000) and Melillo et al. (1993). Because of the slug's entirely soft-bodied, they are susceptible to reductions in rainfall. The species at different stage of their life, have different shapes, structures and the chemical compounds.

The chemical compounds, structure and the shape of the species which are affected by climate change, are very important for mollusc palatability.

During this study, the maximum activity of slugs was recorded in early spring and late summer. At this time the weather was colder and wetter. The results showed that rises in temperature reduced mollusc activity.

On the other hand, increasing precipitation enhanced slugs' activities. This study showed that all environmental factors have important effects on molluscs' behaviours, but their interaction will be more critical. At Ambient $-50 \%$ of moisture availability and Ambient $+3{ }^{\circ} \mathrm{C}$ of temperature, the slugs hardly had any activity. While at Ambient $+50 \%$ level of water and ambient temperature and also Ambient $+3{ }^{\circ} \mathrm{C}$, they showed their maximum activities. Increasing temperature and decreasing humidity are two reasons for the appearance of small and tiny hair (in terms of size and number) on the leaves of plant species. It is the reaction of the species to drought situations which can usually, (but not always) make the species unpalatable to molluscs. Because the snails have a shell, they can better manage water loss. So they are generally able to feed better than slugs under drier conditions.

What was apparent from observing the experiment was that mollusc feedings tended to vary greatly depending on the abundance of plant species, and, in particular, the abundance of palatable species. On the other hand, a community of palatable species, providing a good situation for mollusc activity in terms of humidity and temperature helps them to select their food.

They reduce some species, allowing the other to receive more space to grow and develop as well as more light and nutrition. Therefore, mollusc grazing affected the competition between species in the plant community. As a result, the flowering development and flowering period of the species were affected by mollusc grazing as well. With adding more palatable spices to the designed plant community, we can keep our valuable species within a plant community (Figs. 20 and 21).

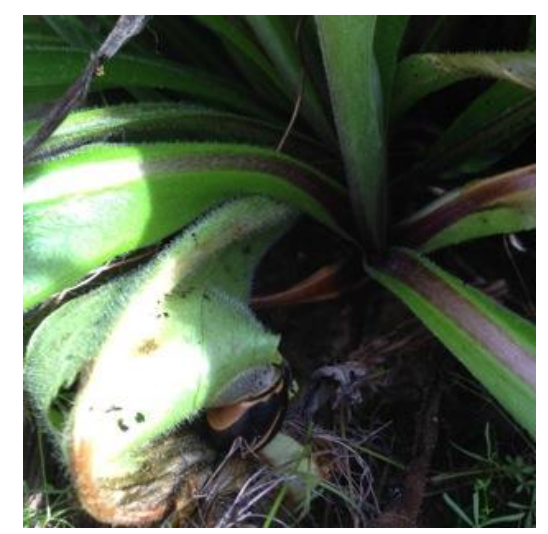

Figure 20. Snail grazing a necrotic area on a hairy leaf 


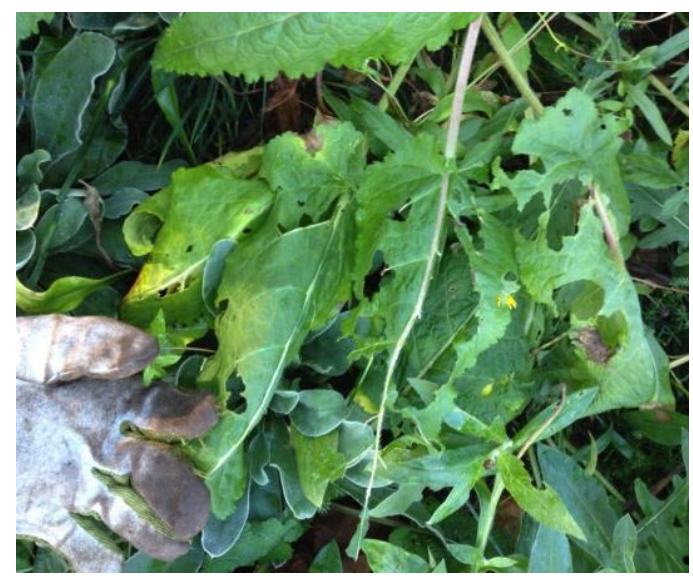

Figure 21. Effects of mollusc grazing on Salvia nemorosa

\section{Comparison of mollusc and non-mollusc experimental areas}

The well and poorly fitted species show overall similar (but not equal) patterns of biomass productivity when exposed to the mollusc grazing. In the well-fitted group, even the mollusc friendly environment produced slightly less biomass, which can be attributed to the contribution to the biomass of Bupthalmum salicifolium and Centaurea montana. The intermediate fitted group shows an apparent decrease in biomass production as a result of mollusc grazing. This pattern suggests that when mollusc species selectively choose palatable plants, the other less favourable or unpalatable plants have a more favourable environment to grow and face less competition in their ambient environment. It can lead to their overall better growth that compensates for the biomass lost to molluscs. Unlike the well-fitted species, the unpalatable plant species cannot produce enough biomass in the intermediate fitted group. When the studied ecological groups were exposed to combined effects of the moisture and treatment variations in mollusc friendly and non-mollusc environments, they showed that increasing moisture would increase their activity and therefore, the grazing levels. Though the plant species grow better when they are exposed to more moisture, the presence of molluscs prevents these species from reaching their full biomass productivity potential in the new growth environment. It also can be deduced that when the mollusc selectively chooses palatable species for grazing the unpalatable plants face less competition and can compensate removed biomass of palatable plants. The increased temperature when more moisture is also available does not have a tangible effect on the mollusc grazing providing adequate moisture is available. The intermediate fitted group clearly showed when the unpalatable species cannot compensate the palatable species biomass removal in mollusc friendly areas, how dramatic is the impact of mollusc grazing on biomass productivity. For instance, for this group, the biomass productivity has reduced by half in the Ambient $+50 \%$ moisture and Ambient $+3{ }^{\circ} \mathrm{C}$ Temperature when these species are exposed to mollusc grazing.

\section{Well fitted species}

The palatable species in this group (Arnica montana, Bupthalmum salicifolium, Centaurea montana, Phyteuma spicatum var. caeruluem, Salvia pratense, Scabiosa 
caucasica) to some extent reacted differently to molluscs when exposed to different moisture levels. Although, Bupthalmum salicifolium, Centaurea montana at the outset of the experiment were considered as palatable species (based on previous experimental work) these two species proved to be unpalatable in this study. Not surprisingly all of the unpalatable species Galium verum, Geranium sylvaticum, Knautia arvensis, Knautia arvensis, Origanum vulgare, Prunella vulgaris and Primula veris showed better growth and more biomass productivity with increasing moisture availability. It can be because of two reasons, the first one is the positive impact of moisture on these species' growth, and the other one is less competition for light and better-growing conditions. When the palatable species are reduced and consumed due to mollusc grazing, these species have a better environment for growth. Exposure to the higher temperature, Ambient $+3{ }^{\circ} \mathrm{C}$, supports this finding. The plant species in this group show a slight increase in biomass productivity; however, interestingly the palatable species fail to survive in higher moisture levels. Higher temperature leads to less moisture due to evaporation. Mollusc grazing is reduced when soil is less moist, and therefore we see better growth even for the palatable species. During Year 2, more biomass productivity is observed for the species in the well-fitted group. It is compatible with the findings of Hithmough and Wagner (2011) that suggest some of the plant species that were heavily consumed by mollusc grazing in the first year when smaller and more juvenile could show considerable growth during the Year 2.

The combined effects of the moisture and temperature treatments are in line with the above findings. Apart from Bupthalmum salicifolium and Centaurea montana that produces biomass under the different combined treatment, other palatable species; Arnica montana, Phyteuma spicatum var. caeruluem, Salvia pratense, and Scabiosa caucasica retain their biomass only when the moisture levels are at Ambient $-50 \%$. It indicates that grazing activities with increasing moisture levels are enough to eliminate these plants. Even for these species under the Ambient - 50\% moisture level, Ambient $+3{ }^{\circ} \mathrm{C}$ temperature leads to better growth, which is due to reduced activity of mollusc species. It is assumed that increased biomass productivity of Bupthalmum salicifolium, Centaurea montana when grazing conditions are suitable, is due to the presence of alkaloids and other toxic molecules in the leaves of adult plants.

\section{Intermediate fitted species}

Among the three ecological groups in this research, the intermediate fitted group species clearly show the most significant impact of grazing on their biomass productivity. Asphodeline lutea, Centaurea triumfetii, Centaurea orientalis, Hedysarum hedysaroides and Paradisea liliastrum are palatable to highly palatable species that disappear with increasing moisture levels. With increasing the moisture levels leads to better biomass productivity for the Dianthus carthusinorum, Euphorbia nicaensis, Linum flavum 'Compactum', Linum narbonennse, Lychnis coronaria, Lychnis flos jovis unproductive plant species. The same growth pattern was expected for the palatable species because of the high moisture levels, but they disappeared when the temperature reaches Ambient and Ambient $+50 \%$ moisture levels. Again, this can be attributed to higher mollusc grazing due to more available moisture. Similar to the well-fitted group these plant species show a slight increase with increasing temperature to Ambient $+3{ }^{\circ} \mathrm{C}$.

Interestingly all of the palatable species are present when the temperature increases. Higher temperature, more evaporation and less available moisture to molluscs, hampers 
their grazing, which causes more biomass productivity at the higher temperature treatment. For the combined water and temperature treatment, the plants in the intermediate fitted group produce their least amount of biomass if the water treatment is at Ambient $-50 \%$ and the temperature is Ambient $+3{ }^{\circ} \mathrm{C}$. Although many of these species naturally grow in landscapes that experience significant drought in summer, many of these species grow earlier in the year thus avoiding the most severe moisture stress. While the highest biomass production belongs to Ambient $+50 \%$ and Ambient $+3{ }^{\circ} \mathrm{C}$. Increasing mollusc activities due to the more available moisture was neutralized by higher temperature levels. The palatable species in this group; Asphodeline lutea, Centaurea triumfetii, Centaurea orientalis, Hedysarum hedysaroides, Paradisea liliastrum and Salvia nemorosa are all naturally distributed in parts of Europe and Eurasia with prolonged dry conditions in summer. The exception to this is Paradisia, which occurs at moderate altitudes in the Alps at which slug populations are small or absent. These species are likely to become better fitted to Southern Britain in the future where climate change models currently predict drier spring to autumn conditions.

\section{Poorly fitted species}

The plant species disappear when the moisture availability levels reach Ambient $+50 \%$. Some of the species show biomass productivity when the moisture is at the ambient level. These plant groups are mostly native of the continental temperate steppe grassland and cannot tolerate higher moisture levels. At lower levels of moisture in these habitats, molluscs are mostly absent, and hence these species are potentially palatable. Balsmorrhiza sagitifolius, Centaurea pulcherrimus, Delphinium barbeyi, Dracocephalum grandiflorum and Hymenoxys grandiflora are the palatable species in this group. When the moisture levels reach Ambient and Ambient $+50 \%$ even if some of the palatable species can survive the moisture level and consequently the increased grazing of mollusc grazing make them disappear. Similar to the well and intermediate fitted group, but to a much higher degree, the plants in this category show better biomass productivity when the temperature is increased. At Ambient $+3{ }^{\circ} \mathrm{C}$, not only all of these species show better growth but also the palatable species are present, which is because of hampered mollusc grazing due to the environmental dryness. These native US and central Asian plant species show their best biomass production when they are exposed to less water and higher temperatures. Not surprisingly the highest biomass production in these species, when exposed to the combined temperature and moisture treatments, belongs to Ambient $-50 \%$ moisture and Ambient $+3{ }^{\circ} \mathrm{C}$ temperature.

\section{How attractive were the communities under different climate change scenarios and mollusc grazing? The design aspect of plant communities}

Todorova (2004) believes that attractiveness of any meadow- like vegetation is related to the factors such as repeating patterns of species in the mix, vegetation structure, flowering colour, and flowering duration. These are very important factors in the urban landscape in the perception of people. As a result, the combination of different flowering species potentially can provide new forms of design impact. The species were used in this research as a new naturalistic design form are attractive for the visitors, and they can provide strong visual impact through flowering in spring, summer, and autumn. During the four growth seasons (2013 and 2016) the flowering period and phenology of the plant species in the community among the different climate scenarios in the presence or 
absence of the molluscs were monitored. Because of parameters such as three levels for water regime, two level of temperature, three ecological groups (well fitted, intermediate fitted and poorly fitted), thirty-six species in two group in terms of mollusc attraction (palatable and unpalatable), the following discussion is based on daily observation and not on statistical data analysis. The phonological aspects of a designed meadow-like grassland community were recorded from the first year of the growing season. Results from the experiments showed the flowering phenology of species in the community was affected by temperature, moisture availability and also mollusc grazing. However, the Interaction of these environmental factors was more important. The results indicate that the temperature is imperative for flowering initiation and development. While the water regime is more critical for the flowering period. Mollusc grazing affected the flowering development and flowering period by reducing the competition between species in the plant community. They reduce some species and let the other species receive more space to growth and development, more light and nutrition. A considerable difference between the first year, the second, third and fourth years was observed, but this is normal in sown or planted meadow vegetation. The flowers of most species were observed much later in the first year compared to years 2, 3 and 4. This situation happened because of variation in size and state of development and also because some of the species were not large enough to flower until late in the second year. Almost all species from well-fitted and intermediate fitted species were flowering in the second growing season. The peak attractive flowering impact in year one was August, and in the non-mollusc area and year, two was in July in the mollusc friendly area. The visual impact of the slow-growing species is significant for designing multiple canopy layers of meadow-like communities. They need more time developing, and this, in turn, reduces the aesthetic value of a developing community in the first year. The development of species and their growth rate can also be affected by climate change; the aesthetic characteristics of a designed plant community will be affected by climate change as well (Fig. 22).
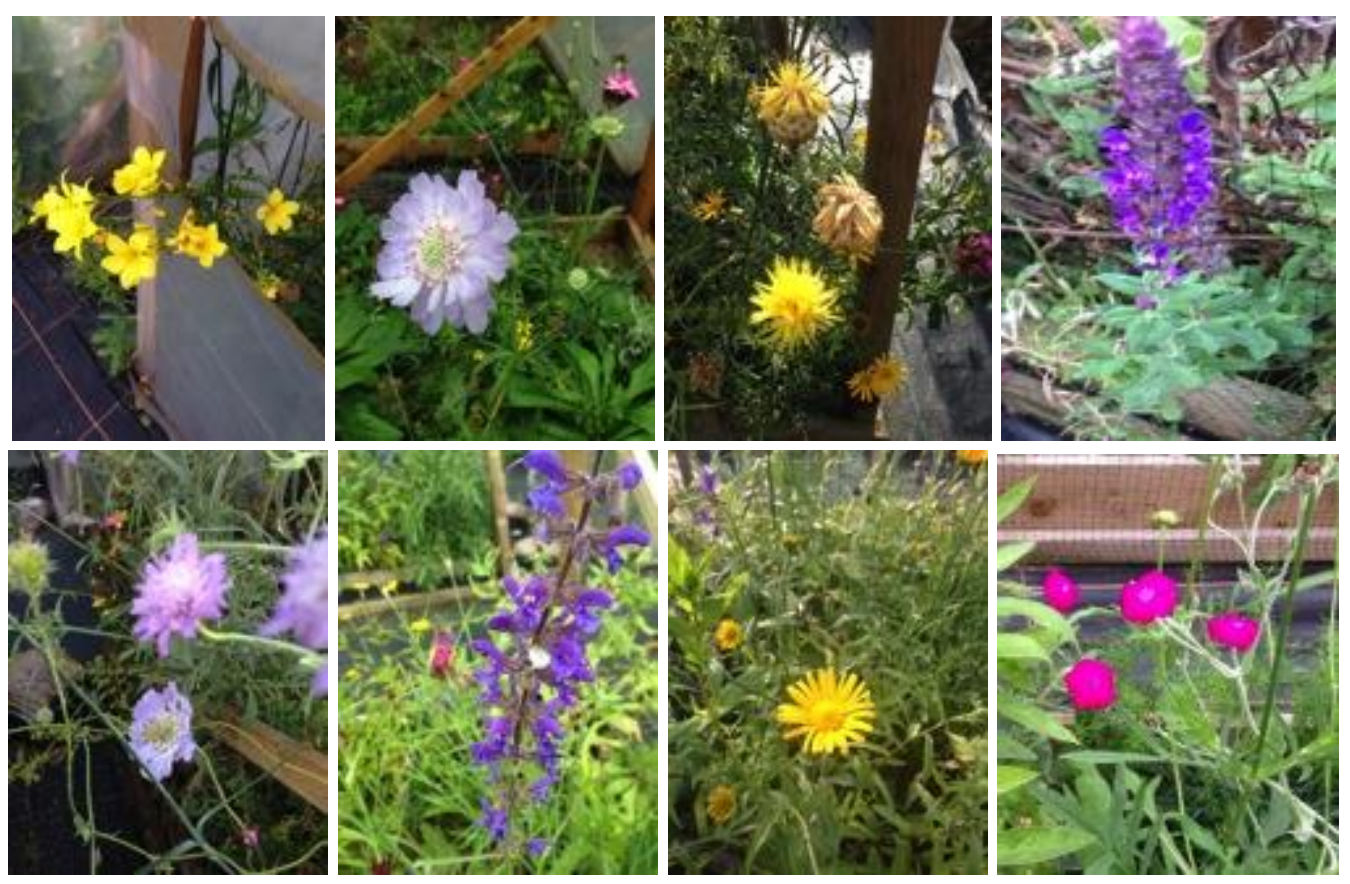

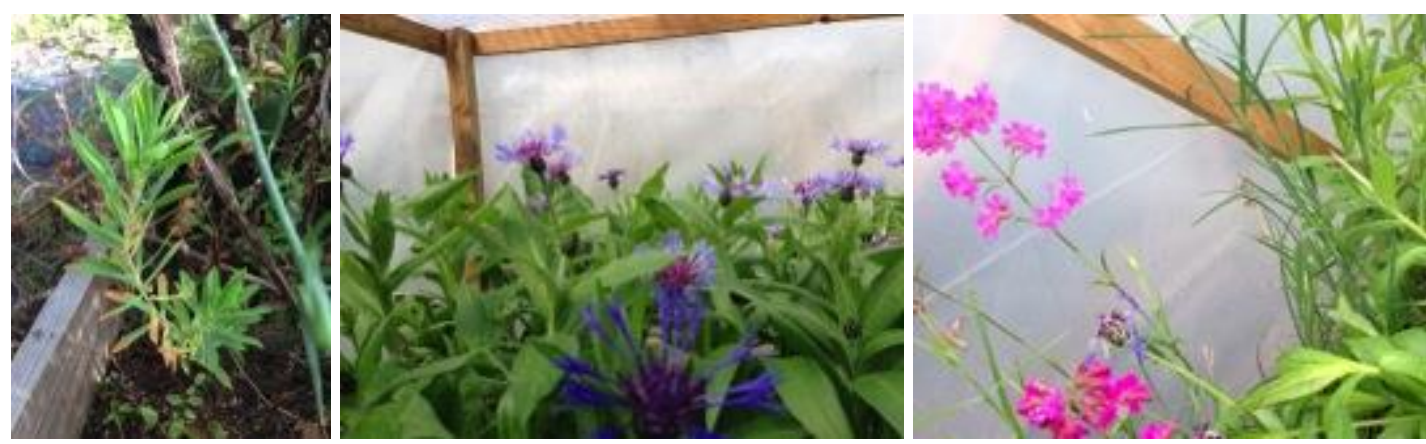

Figure 22. Some plant species of the plant community: Linum flavum 'Compactum', Scabiosa caucasica, Centaurea orientalis, Salvia nemorosa, Knautia arvensis, Salvia pratense,

Bupthalmum salicifolium, Lychnis coronaria, Euphorbia niceaensis, Centaurea montana,

Lychnis flos-jovis

\section{Conclusions}

In this study the effects of slug grazing on "designed plant communities" under different climate scenarios that closely reflected those predicted for 2050 were investigated. The species to develop a meadow- like community were selected from three different habitat types/ecological regions. Mollusc grazing was affected by different climate scenarios (from dry and warm to wet and hot). The molluscs showed different behaviours in dry, wet, warm and ambient temperature, and this led to significant differences in the biomass and structure of these communities. This study provided strong observation support that native fauna such as an insect (bees and hoverflies) and mollusc (slug and snail) were supported by non-native as well as native species of the plant community. It was clear that the flowers of many species in the community were attractive to generalist pollinators. Because of the long period of flowering time through the different species and different treatment as well, the plant community provided an excellent habitat for insect activity.

In this study, the impact of climate change and slug grazing on designed plant community (36 species) were investigated. Independent research about the impact of mollusc grazing on each species under current UK climate situation and future climate scenarios of UK is recommended.

More studies about the possibility of keeping the valuable species in the urban landscape with offering the more palatable species for the molluscs and less useful species for the greenspace are recommended as well.

\section{REFERENCES}

[1] Ahmad, H., Hitchmough, J. D. (2007): Germination and emergence of under storey and tall canopy forbs used in naturalistic sowing mixes. A comparison of performance in vitro $\mathrm{v}$ the field. - Seed Science and Technology 35(3): 624-637.

[2] Alizadeh, B. (2016): The impacts of climate change on designing sustainable urban landscapes. - Doctoral Dissertation, University of Sheffield, Sheffield.

[3] Alizadeh, B., Hitchmough, J. (2019a): A review of urban landscape adaptation to the challenge of climate change. - International Journal of Climate Change Strategies and Management 11(2): 178-194. 
[4] Alizadeh, B., Hitchmough, J. D. (2019b): Designing sustainable urban landscape and meeting the challenge of climate change: a study of plant species adaptation and fitness under different climate change scenarios in public landscape of UK. - Landscape Research 45(2): 228-246.

[5] Bakkenes, M., Alkemade, J. R. M., Ihle, F., Leemans, R., Latour, J. B. (2002): Assessing effects of forecasted climate change on the diversity and distribution of European higher plants for 2050. - Global Change Biology 8(4): 390-407.

[6] Briner, T., Frank, T. (1998): The palatability of 78 wildflower strip plants to the slug Arion lusitanicus. - Annals of Applied Biology 133(1): 123-133.

[7] Bruelheide, H., Scheidel, U. (1999): Slug herbivory as a limiting factor for the geographical range of Arnica montana. - Journal of Ecology 87(5): 839-848.

[8] Dirzo, R. (1980): Experimental studies on slug-plant interactions. I. The acceptability of thirty plant species to the slug Agriolimax caruanae. - Journal of Ecology 68: 981-998.

[9] Dunnett, N., Hitchmough, J. (2004): The Dynamic Landscape: Design, Ecology and Management of Naturalistic Urban Planting. - Taylor \& Francis, London.

[10] Fenner, M., Hanley, M. E., Lawrence, R. (1999): Comparison of seedling and adult palatability in annual and perennial plants. - Functional Ecology 13(4): 546-551.

[11] Frank, T. (2003): Influence of slug herbivory on the vegetation development in an experimental wildflower strip. - Basic and Applied Ecology 4(2): 139-147.

[12] Grime, J. P. (1973): Competitive exclusion in herbaceous vegetation. - Nature 242(5396): 344.

[13] Grime, J. P. (1977): Evidence for the existence of three primary strategies in plants and its relevance to ecological and evolutionary theory. - The American Naturalist 111(982): 1169-1194.

[14] Grime, J. P. (1979): Plant Strategies and Vegetation Processes. - Wiley, Chichester.

[15] Grime, J. P. (1998): Benefits of plant diversity to ecosystems: immediate, filter and founder effects. - Journal of Ecology 86(6): 902-910.

[16] Grime, J. P. (2006): Plant Strategies, Vegetation Processes, and Ecosystem Properties. $2^{\text {nd }}$ Ed. - John Wiley \& Sons, Chicester.

[17] Hitchmough, J. (2011): Exotic plants and plantings in the sustainable, designed urban landscape. - Landscape and Urban Planning 100(4): 380-382.

[18] Hitchmough, J., Wagner, M. (2011): Slug grazing effects on seedling and adult life stages of North American Prairie plants used in designed urban landscapes. - Urban Ecosystems 14(2): 279-302.

[19] Hitchmough, J., Wagner, M., Ahmad, H. (2017): Extended flowering and high weed resistance within two layer designed perennial "prairie-meadow" vegetation. - Urban Forestry \& Urban Greening 27: 117-126.

[20] Holland, K. D., Mcdonnell, M. J., Williams, N. S. (2007): Abundance, species richness and feeding preferences of introduced molluscs in native grasslands of Victoria, Australia. - Austral Ecology 32(6): 626-634.

[21] Hoyle, H., Hitchmough, J., Jorgensen, A. (2017): Attractive, climate-adapted and sustainable? Public perception of non-native planting in the designed urban landscape. Landscape and Urban Planning 164: 49-63.

[22] Hulme, P. E. (1994): Seedling herbivory in grassland: relative impact of vertebrate and invertebrate herbivores. - Journal of Ecology 82(4): 873-880.

[23] Jennings, T. J., Barkham, J. P. (1975): Food of slugs in mixed deciduous woodland. Oikos 26(2): 211-221.

[24] Keller, M., Kollmann, J., Edwards, P. J. (1999): Palatability of weeds from different European origins to the slugs Deroceras reticulatum Müller and Arion lusitanicus Mabille. - Acta Oecologica 20(2): 109-118.

[25] Lawrey, J. D. (1983): Lichen herbivore preference: a test of two hypotheses. - American Journal of Botany 70(8): 1188-1194. 
[26] Magurran, A. E. ((1996): Ecological Diversity and its Measurement. - Chapman \& Hall, London.

[27] Melillo, J. M., McGuire, A. D., Kicklighter, D. W., Moore, B., Vorosmarty, C. J., Schloss, A. L. (1993): Global climate change and terrestrial net primary production. Nature 363(6426): 234.

[28] Nystrand, O., Granström, A. (1997): Forest floor moisture controls predator activity on juvenile seedlings of Pinus sylvestris. - Canadian Journal of Forest Research 27(11): 1746-1752.

[29] Pallant, D. (1972): The food of the grey field slug, Agriolimax reticulatus (Müller), on grassland. - The Journal of Animal Ecology 41(3): 761-769.

[30] Prather, C. M., Pelini, S. L., Laws, A., Rivest, E., Woltz, M., Bloch, C. P., Del Toro, I., Ho, C. K., Kominoski, J., Newbold, T. S., Parsons, S. (2013): Invertebrates, ecosystem services and climate change. - Biological Reviews 88(2): 327-348.

[31] Rathcke, B. (1985): Slugs as generalist herbivores: tests of three hypotheses on plant choices. - Ecology 66(3): 828-836.

[32] Sayuti, Z., Hitchmough, J. D. (2013): Effect of sowing time on field emergence and growth of South African grassland species. - South African Journal of Botany 88: 28-35.

[33] Scheidel, U., Bruelheide, H. (1999): Selective slug grazing on montane meadow plants. Journal of Ecology 87(5): 828-838.

[34] Speiser, B., Rowell-Rahier, M. (1993): Does the land snail Arianta arbustorum prefer sequentially mixed over pure diets? - Functional Ecology 7(4): 403-410.

[35] Team, C. W., Pachauri, R. K., Meyer, L. A. (2014): IPCC, 2014: Climate Change 2014: Synthesis Report. Contribution of Working Groups I. II and III to the Fifth Assessment Report of the Intergovernmental Panel on Climate Change. - IPCC, Geneva.

[36] The London Climate Change Partnership (2018): London's warming - the impacts of climate change on London. - https://ukcip.ouce.ox.ac.uk/wp-content/PDFs/London_tech. pdf (accessed 3 July 2018).

[37] Thomas, C. D., Cameron, A., Green, R. E., Bakkenes, M., Beaumont, L. J., Collingham, Y. C., Erasmus, B. F., De Siqueira, M. F., Grainger, A., Hannah, L., Hughes, L. (2004): Extinction risk from climate change. - Nature 427(6970): 145.

[38] Todorova, M. (2018): What Is or Is There a Balkan Culture, and Do or Should the Balkans Have a Regional Identity? - In: Todorova, M. (ed.) Scaling the Balkans. Brill, Leiden, pp. 221-231.

[39] Vörösmarty, C. J., Sahagian, D. (2000): Anthropogenic disturbance of the terrestrial water cycle. - Bioscience 50(9): 753-765.

[40] Wardle, D. A., Barker, G. M., Bonner, K. I., Nicholson, K. S. (1998): Can comparative approaches based on plant ecophysiological traits predict the nature of biotic interactions and individual plant species effects in ecosystems? - Journal of Ecology 86(3): 405-420.

[41] Wilby, A., Brow, V. K. (2001): Herbivory, litter and soil disturbance as determinants of vegetation dynamics during early old-field succession under set-aside. - Oecologia 127(2): 259-265. 